\title{
A Strategy to Decorate the Surface of NPs and Control their Locations within Block Copolymer Templates
}

\author{
Misang Yoo ${ }^{1}$, Joona Bang1, \\ Kwanyeul Paek ${ }^{2}$ and Bumjoon J. Kim ${ }^{2}$ \\ ${ }^{1}$ Department of Chemical and Biological Engineering, Korea University, \\ ${ }^{2}$ Department of Chemical and Biomolecular Engineering, \\ Korea Advanced Institute of Science and Technology, \\ Republic of Korea
}

\section{Introduction}

Polymer nanocomposites consisting of polymers and inorganic nanoparticles (NPs) have attracted many attentions due to their promising potentialsof diverse applications such as solar cell, sensors, catalysts, ferroelectric devices, etc. To impart sufficient stability of NPs and integrate NPs into polymer matrix, it is a prerequisite that the surface of the NPs is properly treated with various ligands having desired properties. Up to date, a number of strategies to synthesize the appropriate gold nanoparticles (Au NPs) have been reported. The most popular method that has been for a long time to prepare Au NPsis to use citrate reduction of $\mathrm{HAuCl}_{4}$ in water, which was introduced by Turkevitch (Turkevich et al., 1951). And this method was developed by Frens to obtain controlled size of Au NPs from 10 to 100 $\mathrm{nm}$, via varying the concentration ratio between $\mathrm{HAuCl}_{4}$ and sodium citrate (Frens, 1973). In organic solvent, the so called "two-phase method" developed by Brust et al. has a considerable impact in this field until today due to the facile synthesis of stable Au NPsthat are protected by alkanethiols with controlled size and monodispersity (Brust et al., 1994). Later, they also introduced the "one-phase method" in methanol (Brust et al., 1995) and Yee et al. have expanded this method to various metal NPs such as gold, palladium and iridium in tetrahydrofuran (Yee et al., 1999). Furthermore, Hostetler et al. demonstrated that the functionality of monolayer protected NPs can be further enhanced via ligand exchange method (Hostetler et al., 1999).

Recently, the inorganic NPs which is surface modified with polymeric ligands instead of the small surfactant molecules, such as alkanethiols or citrate, have attracted great interest as they can provide not only the improved stability but also various functionalities, unique structure and characteristics, and compatibility with other matrices. As a versatile approach for the surface modification of NPs, it has been shown that various polymers can be grafted onto the NP surface via "grafting-from", "grafting-to", "ligand exchange" or "templating" methods. In the "grafting-from" method, polymers are usually grown from the NP surfacesvia living-free radical polymerization, which are modified with the initiators. In contrast, when the end-functionalized polymers are synthesized, such as thiol-terminated 
polymers, they can be directly grafted onto the NP surface. In both methods, it has been demonstrated that the surface of various NPs can be successfully modified with desired polymeric ligands to fabricate the well-defined nanocomposites. For example, the location of the NPs within block copolymers can be precisely controlled. When the NP surface is modified with one block, it was shown that the resulting NPs are located at the corresponding domain. The more interesting issue is to control the location of NPs at the interface of $\mathrm{AB}$ block copolymers. In this case, it was shown that the decoration of the NP surface with a mixture of A/B homopolymers can result in the "Janus" type amphiphilic NPs and hence they are located at the interface of AB block copolymers. This "Janus" type NPs provide a practical method for producing nanostructures that are amenable to technological applications. For examples, they can be used as templates to transfer the copolymer structure into the substrate, i.e., nanoreactors where catalysts can be anchored to the base of the pores, and photoelectrochemical applications. In this chapter, we will cover aforementioned issues, NP surface modification, the control of NPs within the block copolymers and their applications.

a. Grafting from method
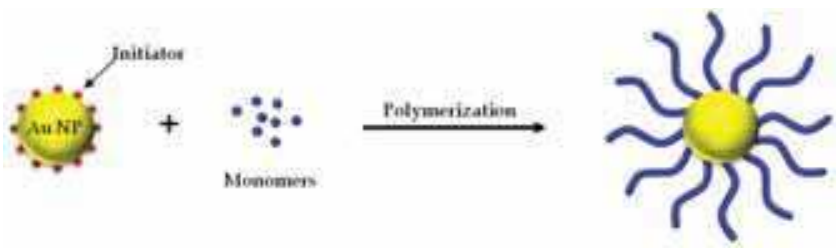

b. Grafting to method

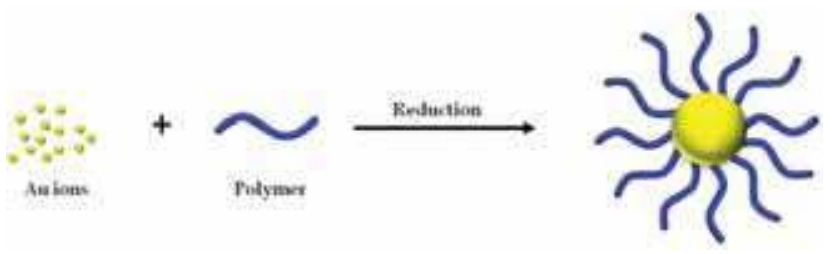

c. Ligand exchange
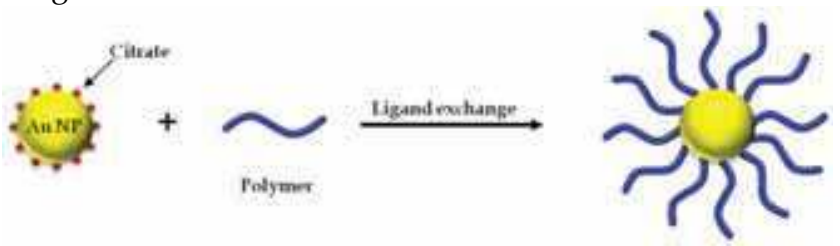

d. Templating
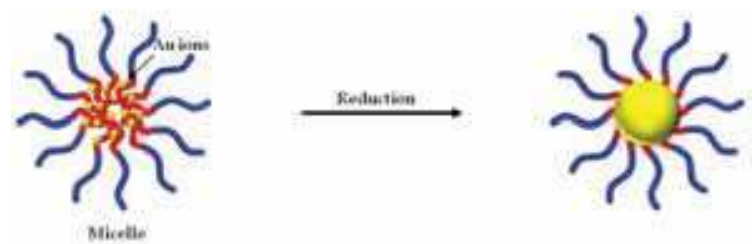

Fig. 1. Schematic illustration to prepare the surface modified Au NPs via (a) grafting from, (b) grafting to, (c) ligand exchange and (d) templating methods. 


\section{Decoration of nanoparticle surface}

\subsection{Grafting from approach}

In "grafting from" method, the surface initiated NPs are preformed and polymers are grown directly from the surface of the NPs.To synthesize the polymers, various polymerization techniques were reported. The most prevalent technique is the living radical polymerizations, such as atom transfer radical polymerization (ATRP), reversible additionfragmentation chain transfer (RAFT), due to its simplicity and versatility. Especially, the main advantage of combining the "grafting from" method with the living radical polymerization is not only the control of molecular weight of polymer but also the possibility to achieve higher surface grafting density of polymer brush. In "grafting to" method, it is difficult to obtain high grafting density because of the steric hindrance of polymer ligands. But in case of "grafting from" method, the polymer brushes grow from the initiators on the surface of NPs, and hence the high grafting density of polymer brush can be obtained. The initiator is usually anchored on the surface of NPsusing disulfide initiator or by reacting with active group such as hydroxyl, carboxylic acid, amine, etc. As an example, Raula and coworkerssynthesized $\mathrm{Au}$ NPs coated with 11-mercapto-1-undecanol and subsequently modified the Au NPs into RAFT agent which has carboxylic acid at the end (Raula et al., 2003). Then poly( $N$-isopropylacrylamide) (pNIPAM) has been polymerized using RAFT polymerization. They investigated the changes in the surface plasmon of Au NP in different media, and effects of particle concentration, temperature in aqueous solutions. In this case, it was found that the solubility of these Au NPs in water was low due to the low grafting degree of pNIPAM ligands. Kim et al. synthesized the pNIPAM coated Au NPs in aqueous media (Kim et al., 2005). The polymerization initiator, $\left[\mathrm{BrC}\left(\mathrm{CH}_{3}\right)_{2} \mathrm{COO}(\mathrm{CH})_{11} \mathrm{~S}\right]_{2}$, was immobilized to the surface of citrate coated Au NPs by ligand exchange method. The cross-linked pNIPAM ligands were synthesized by ATRP as well as brush type pNIPAM with or without ethylene diacylate as a cross-linker. They compared the thermoresponsiveness of the $\mathrm{Au} \mathrm{NP} / \mathrm{pNIPAM}$ hybrid as function of degree of cross-linking. A similar approach was reported using a different cross-linker (Li et al., 2007). The preformed $\mathrm{Au}$ NPs were modified by disulfide initiator and the pNIPAM chains were grown in the presence of $N, N$-methylenebisacrylamide (MBAA) as cross-linker via ATRP. As a result, the slightly cross-linked Au NPs can be used to trap and encapsulate other NPs, biomolecules, dyes, or drugs by a temperature-introduced "breathing" process. Later, they also fabricated $\mathrm{pH}$ responsive Au NPs which were modified with poly(4-vinylpyridine) (P4VP) using the similar approach(Li et al., 2007). At low pH, the polymer layer of Au NPs is loosely swollen because of the pyridyl groups, which are facially protonated and positively charged. At high $\mathrm{pH}$, the $\mathrm{Au}$ NPs were aggregated due to the collapse of polymer layers. Such Au-P4VP nanocomposites as a smart supporter can entrap transition metal ions by their efficient coordinating segments, and the metal ions can be reduced in situ to construct the novel $\mathrm{pH}$ stimuli bimetallic catalysts.

Recently, the Au NPs which are conjugated with biomolecules like DNA and protein have attracted great interest due to the potential use of the programmability for diverse application from biosensing, biodiagnostics to nanoelectronics. Especially, DNA was chosen as a polymeric material in many researches due to the specificity of DNA base-pairing, the predictability of inter- or intramolecular interactions, its physicochemical stability, and mechanical rigidity. Zhao et al. polymerized long single-stranded DNA on Au NPs via rolling circle amplification (RCA) reaction catalyzed by a special DNA polymerase known 
as $\Phi 29$ DNA polymerase (Zhao et al., 2006).Thiol-modified DNA primers were functionalized onto the $15 \mathrm{~nm}$ diameter Au NPs prepared by the classical citrate reduction. A 63-nucleotide-long circular DNA template was annealed with the Au NPsand then RCA was carried out for long single-stranded DNA polymerization. The resulting DNA-Au NP conjugates were used as 3D scaffolds for further nano-assemblies by incubating long DNA$\mathrm{Au}$ NP with $5 \mathrm{~nm}$ Au NPs that were modified with a 25-nt antisense oligonucleotide. Also, $\mathrm{Au}$ NPs having peptide chains on the surfaces have been prepared by Higuchi et al. via ring-opening polymerization of $\gamma$-methyl L-glutamate $N$-carboxyanhydride with fixed amino groups on the NP surface as an initiator (Higuchi et al., 2007). The peptide-Au NPs, whose peptide chains havea-helical conformation, formed a fibril assembly owing to the dipole-dipole interaction between the peptide chains on the distinct NPs. On the other hand, when the peptide chains on the surface adopt a random coil conformation, individual peptide-Au NPs existed in dispersed form.

(a)
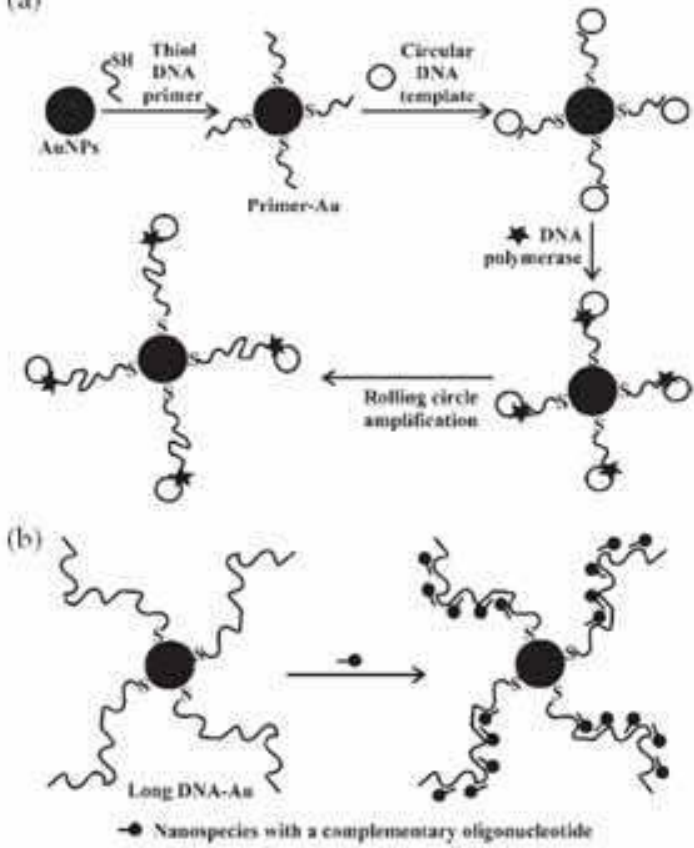

(c)

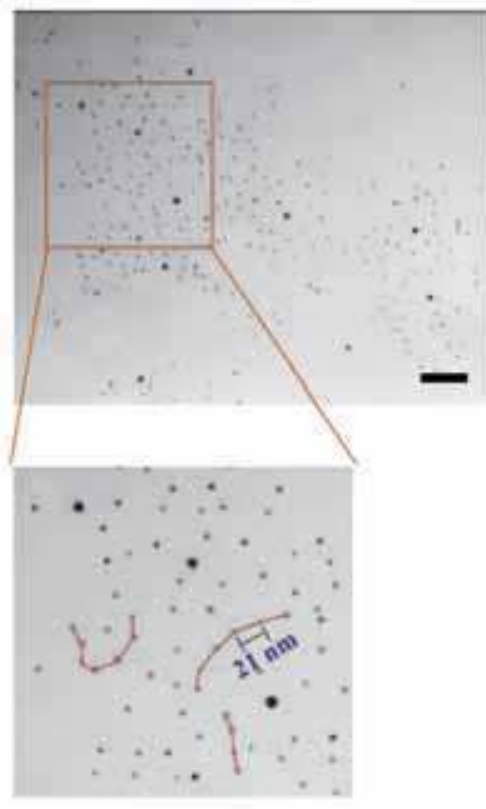

Fig. 2. Schematic illustration of (a) rolling circle amplification (RCA) reaction on AuNPs. (b) DNA-Au NP conjugates produced by RCA as a scaffold forthe formation of 3D nanostructures. (c) TEM images of nano-assembled superstructures prepared from $5 \mathrm{~nm} \mathrm{Au}$ NPs modified with antisense DNA and long DNA-Au scaffolds. Scale bar: $100 \mathrm{~nm}$ (Zhao et al., Angew. Chem. Int. Edit., 2006, 45, 2409. Copyright Wiley-VCH Verlag GmbH \& Co.

$\mathrm{KGaA}$. Reproduced with permission.)

Until now, the special affinity between thiol (-SH) and gold is mainly used to attach polymers to the Au NPs surface. However the reversible nature of the Au-thiol bond, which allows ligand escape above $60{ }^{\circ} \mathrm{C}$, significantly hampers the stability of the Au NPs. Many groups tried to enhance the thermal stability of Au NPs through the introduction of cross- 
linking of polymeric shell or protective inorganic shell. Kotal et al. synthesized Au-PMMA NPs by ATRP at the elevated temperature (Kotal et al., 2005). The cross-linked siloxane primer layer on the Au NP surface, resulting from the hydrolysis of trimethoxysilane tail group of 3-mercaptopropyltrimethoxysilane, was used to attach the initiators and stabilized the initiator-containing surface to high temperature ATRP. Matyjaszewski group recently demonstrated the one pot synthesis of stable Au NPs protected with a cross-linked shell and linear tethered polymer brushes by "graftingfrom" approach (Dong et al., 2008).The synthesis of cross-linked polymeric shell is accomplished by adding n-butyl acrylate monomer and the dimethacrylate as cross-linker at the beginning of ATRP. The reactivity of the monomer is much lower than that of the cross-linker, therefore, the cross-linker was consumed faster than the monomer and was preferentially incorporated into the crosslinked shell. The subsequent polymerization of the remaining monomer formed the linear brush layer. The resulting Au NPs solution was heated up to $110{ }^{\circ} \mathrm{C}$ to test the thermal stability and exhibit almost same plasmon band in UV-vis spectra before and after heating.

\subsection{Grafting to approach}

In "grafting to" method, polymers end-capped with thiol groups or containing disulfide units have been used to directly attach polymer ligands on Au NPs via the two-phase method (Brust method) or one-phase method. Since the polymer ligandsusually prepared via living/controlled polymerization prior to being employed to synthesis of Au NPs, the desirable properties of polymer such as chain length, architecture, composition and functionality can be precisely designed. Recently, the RAFT polymerization has been more widely used than other techniques, such as NMP and ATRP, as it has a wide choice of monomer to polymerize and doesn't require a special metal catalyst. Especially, the main advantage of RAFT polymerization is that the dithioester group existed at the end of polymer can be readily converted to the thiol group by reduction reaction with base. Therefore,the resulting polymers can be used for the surface modification of various metal NPs such as CdSe, Pt and Au. In this case, both the two-phase and one-phase methods were modified by introducing polymer ligands instead of dodecanethiol or octadecanethiol in the original procedure.Corbierre et al. synthesized Au NPs modified with tetradecanethiol $\left(\mathrm{C}_{14^{-}}\right.$ $\mathrm{SH}$ ) or thiolated polymers (PS-SH and PEO-SH) by one-phase method in THF (Corbierre et al., 2004). They compared the grafting densities of polymers on Au NPs and either on flat gold surface. In this case, increasing the chain length leads to an increase in the steric hindrance of ligands, resulting in decreasing the corresponding surface density both on $\mathrm{Au}$ NPs and on flat Au surfaces. Overall, it was found that the grafting density on the curved NPswas higher than that on the flat surface, and, this effect is larger in polymer ligands than small ligands.This is because the presence of the voids at the facet edges results in extra volume for grafting the polymeric ligand and the percentage of void volume is higher for long polymeric ligand than small ligand. Lowe et al. also demonstrated a route for preparing of water soluble Au NPs coated with four different polymers (Lowe et al., 2002). Four (co)polymers have been synthesized by RAFT polymerization in aqueous media: poly(sodium 2-acrylamido-2-methyl propane sulfonate) (PAMPS), poly((ar-vinylbenzyl)trimethylammonium chloride) (PVBTAC), poly( $N, N$-dimethylacrylamide) (PDMA), and poly(3-[2-N-methylacrylamido)-ethyldimethyl ammonio propane sulfonate- $b-N, N$ dimethylacrylamide) (PMAEDAPS- $b$-PDMA). These (co)polymers are composed of an anionic, cationic, neutral, and zwitterionic (betaine) species. The dithioester group at the end 
of polymers was reduced to thiols in aqueous media in the presence of a suitable transition metal complex or metal sol and stabilized the Au NPs. When the reduction takes place in the presence of the PVBTAC (anionic polymer), PDMA and PMAEDAPS- $b$-PDMA, stable colloids are formed. But In case of PAMPS, the Au NPs are not as stable as the others and flocculate readily within $48 \mathrm{~h}$. It was also noted that the NPs coated by PMAEDAPS- $b-$ PDMA are only stable in the presence of salt ( $\mathrm{NaBr}$ in this case) due to the betaine nature. The dithioester end-capped polymer was also used to prepare the Au NPs by Shan et al (Shan et al., 2003). They synthesized the Au NPs coated by three types of pNIPAMligands having different end groups or using different synthesis method. The first type was comprised of pNIPAM with narrow molar mass distributions, synthesized by RAFT polymerization and thus bearing a dithioester at the chain end. These polymers were used directly to passivate the Au NPs upon the one-phase method. The second type of ligand was derived from the first one through hydrazinolysis, and they therefore contained a thiol end group. The third type of ligand was pNIPAMs obtained through conventional radical polymerization, postmodified to contain thiol end groups. But the modification efficiency was not high and the resulting Au NPsprotected with this type of pNIPAM tended to crosslink into a network. On the other hand, either by directly using pNIPAM containing dithioester at chain end or by using thiolated pNIPAM obtained via hydrolysis of the first type, the Au NPs were successfully prepared. They also investigated thermal properties of pNIPAM coated Au NPs in water (Shan et al., 2004). They observed the two separate phase transitions of the pNIPAM chains on Au NPs, different from that of the corresponding free pNIPAM dissolved in water. The first transition with a sharp and narrow endothermic peak occurs at lower temperature, while the second one with a broader peak occurs at higher temperature. The observations are tentatively rationalized by assuming that the pNIPAM brush can be subdivided into two zones, the inner shell and the outer shell. In the inner shell, the pNIPAM segments are close to the gold surface, densely packed, less hydrated, and undergo the first transition. In the outer shell, the pNIPAM segments are looser and more hydrated, adopt a restricted random coil conformation, and show a phase transition, which is dependent on both concentration of Au NPs and the chemical nature of the end groups of the pNIPAM chains.

Recently, several groups have demonstrated the preparation of the amphiphilic Au NPs coated by two different polymeric ligands. Shan et al. prepared the amphiphilic Au NPs grafted with a mixture of pNIPAM and polystyrene (PS) by one-phase method in a homogenous THF phase (Shan et al., 2005). The pNIPAM and PS chains have dithioester group because they were synthesized by RAFT polymerization and directly used to passivate the Au NPs without further modification as their previous work. Monolayer of the amphiphilic Au NPs at the air/water interface was built up by employing a Langmuir trough. During the compression of the monolayer, they observed several characteristic regions that can be ascribed to the pNIPAM conformational transition affecting the optical properties. They concluded that the chemically different pNIPAM and PS chains grafted on the gold core tend to be phase separated through the contact angle measurements on the upper and lower surfaces of the Au NPs monolayer. They also investigated the surface plasmon resonance and the thermal responsiveness of the amphiphilic Au NPs monolayer (Shan et al., 2006). The surface plasmon resonance band of the monolayer undergoes a blueshift as the surface pressure increases which is closely related to the conformational change of pNIPAM chains. In contrast, the UV-vis absorption spectra of the Au NPs multilayers 
transferred at different temperatures onto slides have been measured and showed a redshift in the surface plasmon resonance peak with increasing of the deposition cycle due to the presence of a weak interparticle coupling in the multilayers. However, during the synthesis of the amphiphilic Au NPs, the distribution and exact ratio of polymers attached to the surface of Au NPs may be difficult to control by using two separated polymers as the aforementioned method. Zubarev et al. and Genson et al. prepared the Au NPs which were functionalized with amphiphilic polybutadienen-poly(ethylene glycol) (PB-PEG) V-shaped arms (Zubarev et al., 2006; Genson et al., 2006). First, they prepared a V-shaped PB-PEG amphiphile containing a carboxyl group at its junction point and then the diblock copolymers were attached to the hydroxyl-terminated $2 \mathrm{~nm}$ Au NPs by the esterification. Consequently, $65 \mathrm{~V}$-shaped PB-PEG arms were grafted on a given Au NP, resulting in a high grafting density of 2.94 chains $/ \mathrm{nm}^{2}$. The amphiphilic nature of the Au NPs is expressed in their unique ability to dissolve in any conventional solvent from hexane, benzene, dichloromethane, THF, methanol to water. And these Au NPs formed stable Langmuir monolayers at the air-water and the air-solid interfaces. At these interfaces, the binary arms vertically segregated into a dense polymer corona, which is surrounded the $\mathrm{Au}$ NPs, preventing their large-scale agglomeration and keeping individual NPs well-separated from each other and forming flattened, pancake nanostructures. Wan et al. synthesized the $\mathrm{Au}$ NPs using a hyperbranched polyglycerol that hasa hydrophilic moiety as well as a hydrophobic moiety in one polymer(Wan et al., 2006). The amphiphilic polymer was composed of hydrophobic thioether containing shell and hydrophilic polyglycerol core and used to synthesize the Au NP by two-phase method.
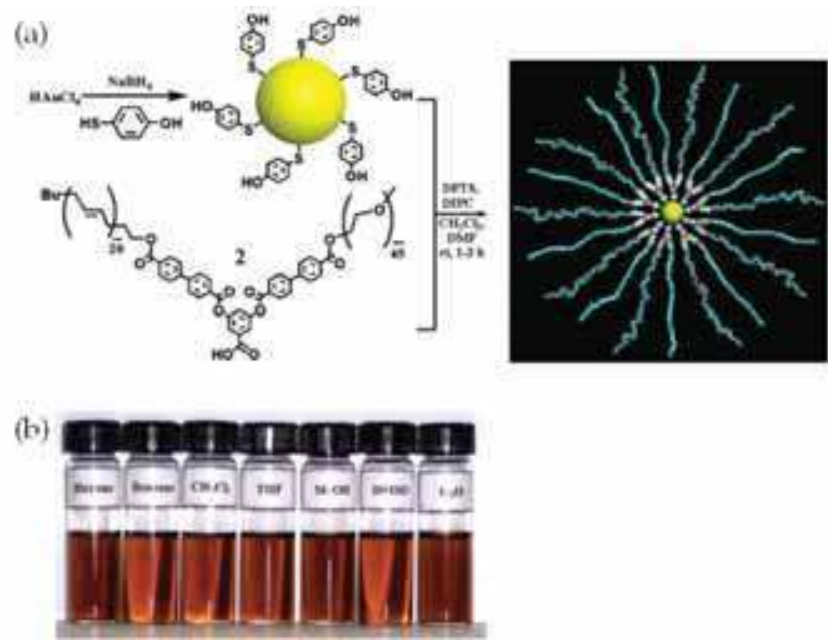

Fig. 3. (a) Synthesis of amphiphilic Au(PB-PEG)n NPs. (b) solutions of amphiphilic Au(PBPEG)n NPs in various solvents (Adapted in part with permission from J. Am. Chem. Soc., 2006, 128, 4958; Langmuir, 2006, 22, 7011. Copyright 2006 American Chemical Society.)

One of most great challenges in the nanotechnology is to synthesize of highly monodisperse $\mathrm{Au}$ NPs as well as control the size of NPs. Digestive ripening, heating a colloidal suspension at or near the solvent boiling point in the presence of a surface-active ligand, was applied to polydisperse colloidal gold in toluene using a series of alkylthiols, viz., octyl-, decyl-, 
dodecyl-, and hexadecylthiols (Prasad et al., 2002). For all cases, the digestive ripening reduced the average particle size and polydispersity significantly. Adjusting the interparticle separation of the Au NPs by the alkyl chain length controls their solubility behavior, leading to the formation of exclusive 2D or 3D superlattices. In case of the Au NPs coated with octanethiol and decanethiol, the stronger and larger 3D superlattices were observed and also lead to large shift in the optical spectra into the near-infrared region. Hussain et al. have demonstrated the size-controlled synthesis of near-monodisperse $\mathrm{Au}$ NPs in the 1-4 $\mathrm{nm}$ range (Hussain et al., 2005). The particle size was controlled by the ratio of gold to capping ligand, a water soluble alkyl thioether end-functionalized poly(methacrylic acid) (PMAA). The Au NPs are readily obtainable in both aqueous solution and nonaqueous solutions. Even though they couldn't give a precise rationalization for their new approach, this simple protocol for the gram scale preparation of monodisperse $\mathrm{Au}$ NPs below $5 \mathrm{~nm}$ has a practical value in various fields where the precise size control and the monodispersity are required.

Recently, the Au NPs conjugated with biomaterials led to new and great development with infinite potential in biotechnology and nanotechnology. Combining the inorganic Au NPs and organic biomaterials brings the synergistic effects that incorporate the highly selective catalytic and recognition properties of biomaterials, such as proteins/enzymes and DNA, with the unique electronic, photonic, and catalytic features of NPs. The excellent biocompatibility and biodegradability of poly( $\varepsilon$-Caprolactone) (PCL) make them well suited for drug and gene delivery and tissue engineering. But their fate in vivo cannot be directly observed by TEM in histological section. Therefore the labeling of PCL biocarrier is desirable by a contrasting agent such as Au NPs which have high electron density. Aryal et al. fabricated the Au NPs grafted with the thiolated PCL by two-phase method as well as ligand exchange (Aryal et al., 2006). The thiolated PCL (PCL-SH) was synthesized through the ring opening bulk polymerization of $\varepsilon$-Caprolactone and removal of protecting group under slightly basic condition subsequently.PCL was also employed forming diblock copolymer to stabilize the Au NPs (Azzam \& Eisenberg, 2007). Poly(ethylene oxide)- $b$ poly(e-caprolactone) (PEO-b-PCL) copolymer was synthesized by ring opening polymerization, and the hydroxyl end group of the PCL block was modified with thioctic acid using dicyclohexyl carbodiimide as the coupling reagent. The resulting PEO- $b$-PCLthioctate ester (TE) was used to passivate the Au NPs by one-phase method in THF. Then micelles in water were prepared by the slow addition of the dilute Au NP solution in DMF into a large excess of water. Under these conditions, the PCL block forms the shell surrounding the gold core, while the PEO block forms the corona. They observed the only micelles with a single gold core per micelle based on the TEM.

On the other hand, DNA or polypeptide grafted Au NPs were investigated by "grafting to" method but there are only a few examples because the Au NPs are usually synthesized through the "ligand exchange" in water for the biocompatibility. Higashi et al. described the preparation of disulfide terminated polypeptide (poly( $\gamma$-benzyl-L-glutamate)) (PBLG) monolayercovered Au NPs via two-phase method(Higashi et al., 2005). The PBLG segments attached on $\mathrm{Au}$ NPadopt a-helix conformation with nearly $100 \%$ content which is much higher value compare to the free PBLG chains in chloroform. They explained that the observed helix enhancement is probably due to PBLG side chain interactions such as $\Pi-\Pi$ stacking of benzyl groups, resulting from characteristic alignment of PBLG segments on Au NPs, at which they are forced to assemble densely.Recently, Cheng et al. applied the DNA 
coated Au NPs to fabricate the free-standing Au NP superlattice sheets (Cheng et al., 2009). First, they prepared monodisperse $13 \mathrm{~nm}$ diameter Au NP capped with 5'-thiolated singlestranded DNA (ssDNA) through the two-phase method. They used the DNA as a dry ligand, similar to alkyl molecular ligands, without the requirement of base-pairing. For further application of superlattices in free-standing electronics, the rigorous control over their internal structures and the overall shapes of discrete features are required. However, in alkyl based fabrication of superlattices, the interparticle spacing is constrained to a small range $(\sim 1.2-\sim 2.3 \mathrm{~nm})$ owing to synthetic limitations on maximum molecular ligand length. Using the ssDNA as a dry ligand is one of methods that can circumvent the above limitations, by combining a microhole-confined, drying-mediated self-assembly process. They obtained discrete, freestanding superlattice sheets in which both structure (interparticle spacings) and functional properties (plasmonic and mechanical) can be rationally controlled by adjusting DNA length. In particular, the edge-to-edge interparticle spacing for monolayered superlattice sheets can be tuned up to $20 \mathrm{~nm}$, which is a much wider range than has been achieved with alkyl molecular ligands.

In common with the grafting from method, many efforts have been devoted to increase the thermal stability of Au NPs through grafting to method.The instability is resulted from the dissociation of polymeric ligand from the surface of Au NPs under high temperature. The stability of Au NPs could be improved through the introduction of multiple thiol-anchoring groups at the polymer chain ends or shell cross-linking of polymeric ligands encapsulating the $\mathrm{Au}$ NPs. Huang et al. prepared the Au NPs coated with poly(p-methylstyrene) containing multiple thioether groups on the chain side (Huang et al., 2005). The synthesis of poly(p-methylstyrene) (PMS) was accomplished via anionic polymerization. The resulting polymer was chlorinated with sodium hypochloriteand the extent of chlorination was determined as $30 \%$ from the ${ }^{1} \mathrm{H}$ NMR.Since a PMS molecule (with a molecular weight of $15,000)$ comprised 127 repeating $p$-methylstyrene units, the $30 \%$ chlorination amounted to 38 chloromethyl groups on each polymer molecule. The chlorinated poly( $p$-methylstyrene) was then reacted with methylthiomethyllithium, which had been prepared via a metalation reaction of dimethyl sulfide with n-butyllithium, to form a styrenic polymer containing thioether groups on the sides of the molecule, PMS- $\left(\mathrm{CH}_{2} \mathrm{SCH}_{3}\right)_{n}$. Au NPs were synthesized in situ in the presence of PMS- $\left(\mathrm{CH}_{2} \mathrm{SCH}_{3}\right)_{\mathrm{n}}$ by borohydride reduction of gold precursor in chloroform phase. Although the PMS- $\left(\mathrm{CH}_{2} \mathrm{SCH}_{3}\right)_{\mathrm{n}}$ coated Au NPs were relatively stable below the $\mathrm{T}_{\mathrm{g}}$ of PMS $\left(\sim 102{ }^{\circ} \mathrm{C}\right)$, the particles were free to move and start clustering at temperatures above the $\mathrm{T}_{\mathrm{g}}$. In TEM micrograph of PMS- $\left(\mathrm{CH}_{2} \mathrm{SCH}_{3}\right)_{\mathrm{n}}$ coated Au NPs after being heated at $150^{\circ} \mathrm{Cfor} 24 \mathrm{~h}$, the clustering of particles was significant. These methods still suffer from a lack of thermal stability and require multistep synthetic approaches.Very recently, Yoo and coworkers reported a simple, yet powerful strategy for preparing thermally stable $\mathrm{Au}$ NPs by introducing photo-cross-linkable azide groups $\left(-\mathrm{N}_{3}\right)$ into the polymeric ligands attached to the gold core (Yoo et al., 2010). Thiol-terminated block copolymers composed of polystyrene and azido-polystyrene, $\mathrm{P}\left(\mathrm{S}-b-\mathrm{S}-\mathrm{N}_{3}\right)-\mathrm{SH}$, were prepared via RAFT polymerization. They designed the ligands in whichthe short PS- $\mathrm{N}_{3}$ block is placed adjacent to the thiol group.Consequently, the gold core can be protected by crosslinked shells after in situ photo-cross-linking to give core-shell nanostructures with welldefined linear polymer chains surrounding a cross-linked polymer shell. The $\mathrm{P}\left(\mathrm{S}-b-\mathrm{S}-\mathrm{N}_{3}\right)-\mathrm{SH}$ coated Au NPs were synthesized by the two-phase method, and the resulting Au NPs were efficiently cross-linked by exposure to UV light subsequently. The cross-linked $\mathrm{Au}$ 
NPsexhibit excellent thermal stability and no aggregation was observed on heating to $200{ }^{\circ} \mathrm{C}$ for extended periods of time in both solutions and nanocomposite films. Furthermore, it was demonstrated that these Au NPscan serve as compatibilizers for thermally annealed PS/PMMA blends. The cross-linked Au NPs were located at the PS/PMMA interface resulting in the reduction in the phase separated droplet size of PS or PMMA. Since the design of the photo-cross-linkable polymeric ligands is modular, the surface property of the $\mathrm{Au}$ NPs can be readily tuned and applied to other functional metal NPs. This facile synthetic method can provide a versatile route to the fabrication of a variety of nanocomposite systems.

(a)
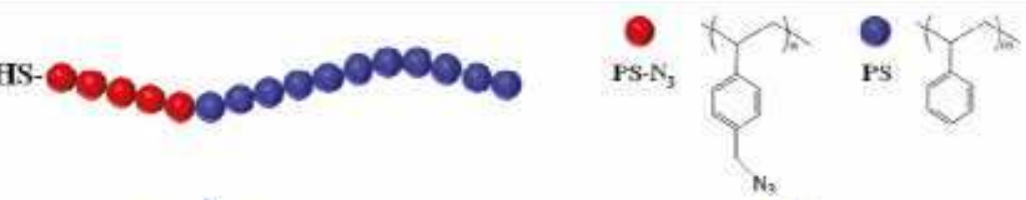

(b)

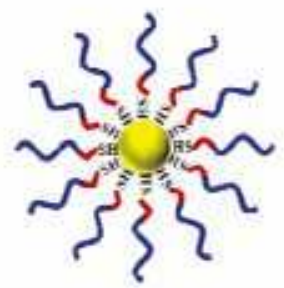

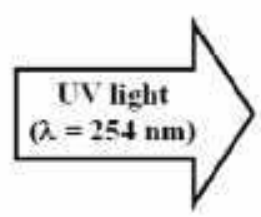

(6)

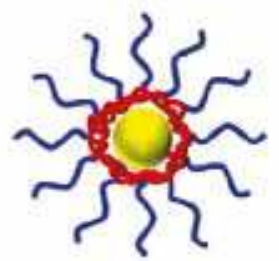

(d)

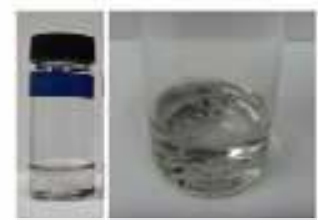

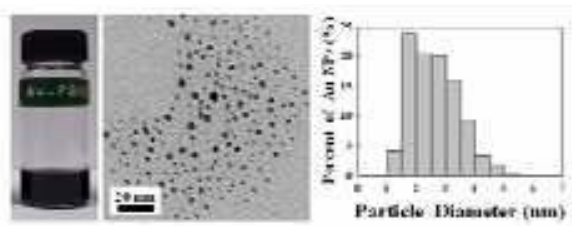

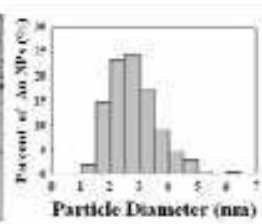

(e)
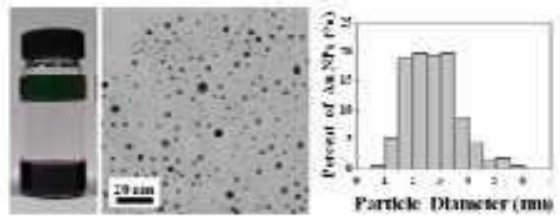

Fig. 4. Schematic illustration for the design of shell-protected Au NPs via UV cross-linking reaction of azido $\left(-\mathrm{N}_{3}\right)$ group. TEM images and the size distribution of (b) PS-Au NPs and (c) cross-linked P(S-b-S-N 3 )-Au NPsbefore heating. (d) Photograph image of PS-Au NPs in DBP solution after heating (e) TEM images and the size distribution of cross-linked P(S- $\left.b-\mathrm{S}-\mathrm{N}_{3}\right)$ Au NPs after heating (Adapted in part with permission from Macromolecules, 2010, 43, 3570. Copyright 2010 American Chemical Society.)

\subsection{Ligand exchange approach}

In order to improve the stability of given NPs, the ligands on the surface can be exchanged by others containing new properties or functionalities. In most cases, the incoming ligands 
should bind more strongly to the inorganic NP surface. Au NPs are usually preformed via citrate reduction which is one of the oldest ways to synthesize the Au NPs (Turkevich et al., 1951), prior to the ligand exchange. And the resulting citrate coated Au NPs have high degree of monodispersity with size ranging from 5 to $250 \mathrm{~nm}$. Thus, Au NPs by this method are widely used in not only the areas that require the monodisperse NPs such as electrochemical quantized capacitance charging and single-electron transistor assembly but also in the biotechnology that requires the biocompatibility rather than the two- or onephase method performed in organic media. Mirkin and coworkers have pioneered the DNA linked Au NPs using ligand exchange(Mirkin et al., 1996). The $13 \mathrm{~nm}$ Au NPs were prepared via citrate reduction and they were readily modified with two kinds of thiol-terminated DNA oligonucleotides containing 8-base pair sticky ends which are complementary each other. After an addition of the DNA grafted Au NP aqueous solution to another DNA grafted Au NP solution, an immediate color change is observed from red to purple and a precipitation of the Au NPs ensues resulting from the linking of complementary oligomers anchored on the Au NPs surface. This process can be reversed by thermal denaturation generating the unlinked Au NPs which are soluble in the aqueous solution.

Poly(ethylene glycol) (PEG) is well soluble in a number of organic polar and nonpolar solvents, as well as in water where it is heavily hydrated, forming random coils. Its simple structure and chemical stability make them inert and biocompatible. The inertness and nontoxic properties of PEG combined with NPs give rise to a number of applications in medicine, chemistry, or biotechnology. PEG modified NPs are less toxic as well as more stable at high salt concentrations and in biological environments. Niidome et al. developed a technique to modify the gold nanorods with PEG for medical applications (Niidome et al., 2006). Since gold nanorods stabilized with hexadecyltrimethylammonium bromide (CTAB) show strong cytotoxicity, it is not suitable for biological applications. They achieved the PEG modification by adding thiolated PEG in the CTAB coated gold nanorod solution through the ligand exchange, then, excess $\mathrm{CTAB}$ was removed by dialysis. PEG-modified gold nanorods showed a nearly neutral surface and had little cytotoxicity in vitro. Liu et al. reported the assembly of PEG and mixed peptide/PEG monolayers on Au NP surfaces(Liu et al., 2007). The PEG coated or mixed peptide/PEG coated Au NPs were prepared through incubation of citrate coated Au NPs with thiolated PEG and cysteine-terminated peptide. The stability of the resulting bioconjugates in high ionic strength media was characterized as function of NP size, PEG length, and monolayer composition. They found that the Au NP stability increases with increasing PEG length, decreasing particle size and increasing PEG mole fraction. Also, mixed monolayers prepared via the sequential addition of PEG followed by peptide were more stable than particles prepared via simultaneous coadsorption, because the highly cationic, lysine-rich peptide may associate with the anionic $\mathrm{Au}$ NPs more rapidly than the thiolated PEG. As a consequence, the charge on the NPs would be neutralized prior to the formation of a PEG steric barrier.

The modification of other molecules with PEG is often referred to as 'PEGylation'. PEGylation can provide water solubility to hydrophobic materials and PEGylated ligands can be introduced by ligand exchange to Au NPs. Becker et al. demonstrated an efficient way to prepare protein-functionalized Au NPs through theN-terminal modification of the small protein, GTPase Rab6A, with a thiolated PEG linker by native chemical ligation(Becker et al., 2007). The PEGylated proteins were used for immobilization on DNAfunctionalized Au NPs. A ligand exchange reaction with the modified proteins was used to 
displace thiolated oligonucleotides from Au NPs in order to efficiently immobilize protein on the Au NPs. The protein-functionalized Au NPs have potentials for applications as probes in bioanalytical assays and as building blocks for the bottom-up assembly of functional hybrid nanoarchitectures. Bergen et al. presented a model system based on $\mathrm{Au}$ NPs grafting with thiolated PEG and thiolated PEG-galactose for determining optimal physicochemical characteristics for cell-specific delivery in vivo(Bergen et al., 2006). Negatively-charged Au NPs by capping with citrates and positively-charged Au NPs by capping with aminoethanethiol were prepared first, and thenNPs surface was modified by reaction with either PEG-thiol or galactose-PEG-thiol. Modification of the NPs did not significantly affect particle size based on the measurement of dynamic light scattering. The $\mathrm{Au}$ NPs were then exposed tosalt solutions to observe the salt stability. In the presence of salt, it was found that unmodified NPswere aggregated,while PEG modified NPs does not show the aggregation due to the steric stabilization. This platform was applied to screen for NP formulations that demonstrate hepatocyte targeted delivery in vivo. They found that the NP size and the presence of galactose ligands significantly impact the targeting efficiency.

Conjugation of Au NPs with smart polymers such as pNIPAM makes it possible to tailor the electronic and optical properties of hybrid system in response of temperature. Seker et al. have demonstrated a method for fabrication of nanostructured composites featuring simultaneous switching of several optical properties such as color, transparency and metallic luster through remote control of classical coupling in dense pNIPAM coated AuNP arrays (Seker et al., 2005). The pNIPAMs were prepared by RAFT polymerization and subsequently modified chain end group to thiol or disulfide. Au NPs were prepared by the citrate reduction in water then pNIPAM was modified by exchange reaction with weakly bound surface citrate ions. The thin films of pNIPAM/Au NPs can be prepared by simple solution-casting methods. Based on UV-vis spectra of the thin films, they observed that the change in interparticle separation occurs throughout the film. Unaggregated core/shell particles with stimulus-responsive pNIPAM shells of controlled thickness and architecture could generate controlled interparticle separations that govern the optical properties of composite materials. Singh and Lyon demonstrated a synthetic route toward the hollow pNIPAM nanogel via a "seed and feed" method combined with the sacrificial metal NP templating method (Singh \& Lyon, 2007). They prepared citrate capped Au NPs as seeds for polymerization of pNIPAM. Seeds compatible with the precipitation polymerization of NIPAM were formed by the adsorption of a layer of amino-terminated pNIPAM onto the $\mathrm{Au}$ NPs by ligand exchange. Onto these pNIPAM stabilized Au NPs, further pNIPAM shells were synthesized by free-radical polymerization with an addition of acrylic acid as a comonomer to form $\mathrm{pH}$-responsive nanogel particles. To obtain hollow nanogels from the gold core nanogels, the gold core was dissolved by the KCN solution. The resulting sub-50 nm hollow pNIPAM nanogels are ideal for the drug and gene delivery, cellular imaging and nanoreactors.

Block copolymers also have been used to stabilize a variety of NP materials by forming steric or ionic barriers around the particles. Kang and Tatonprepared Au NPs surrounded with shell of amphiphilic poly(styrene- $b$-acrylic acid) (PS- $b$-PAA) in water and permanently fixed them by cross-linking the outer PAA block(Kang \& Taton, 2005). In almost of previous works, the specific chemical interaction of the particle surface and the surface-bound polymer should be explicitly tailored in order to form the shell. But in this case, they used the block copolymer to form shell around the gold core without chemical anchoring. The PS- 
b-PAA copolymers were synthesized by ATRP and dissolved in DMF, which is a good solvent for both hydrophobic (PS) and the hydrophilic (PAA) blocks. Citrate-capped Au NPs were redispersed in DMF. The samples of polymer and NPs in DMF were combined in the presence of 1-dodecanethiol, which hydrophobically functionalizes the surfaces of theAu NPs. Then, water was gradually added to the mixture tosimultaneously desolvate both the particles and the hydrophobicpolymer block from solution and induce the formation of micelles around the NPs. In the absence ofPS-b-PAA, the dodecanethiol-modified NPsprecipitated quickly from DMF as water was added. Inthe absence of dodecanethiol, the NPs remainedoutside the assembled block copolymer micelles. Finally the assembled copolymer micelles containing Au NPs were permanently fixed by cross-linking the PAA block with addition of cross-linkers in water.They also demonstrated the influence on the shell thickness of block copolymer respect to the size of gold core, concentration and composition of block copolymer in this system (Kang \& Taton, 2005). When the feed ratio of block copolymer to the total surface area of gold core is fixed, two different results were observed. For same or lager size of Au NPs than the block copolymer radius of gyration, each core-shell structure consisted of exactly one NP surrounded by a shell of fairly consistent thickness. However, for smaller Au NPs, some structures contained multiple Au NPs that act as solutes and dissolved within the micelle core. When the size of Au NPs is fixed, the shell thickness of block copolymer gradually increases with increasing content of the block copolymer and chain length of block copolymer, as expected. Another type of block copolymer encapsulated Au NP was also reported (Luo et al., 2005). Luo et al. fabricated core/shell Au NPs stabilized with a monolayer of double hydrophilic block copolymer, poly(2-(dimethylamino)ethyl methacrylate)-b-poly(ethylene oxide) (PDMA- $b$ PEO), and demonstrated their stimuli responsiveness before and after shell cross-linking. The PDMA- $b$-PEO diblock copolymer was prepared via RAFT polymerization and the dithioester group was reduced to a thiol group at the chain end. The thiolated PDMA- $b$-PEO was exchanged with citrate grafted onto the preformed $\mathrm{Au}$ NPs and 1,2-bis(2iodoethoxy)ethane (BIEE) was utilized to selectively cross-link the PDMA residues in the inner shell. While both cross-linked and uncross-linked Au NPsexhibited the reversible $\mathrm{pH}$ responsiveness, the shell cross-linked Au NPsexhibited a robust core-shell nanostructure with high colloidal stability.

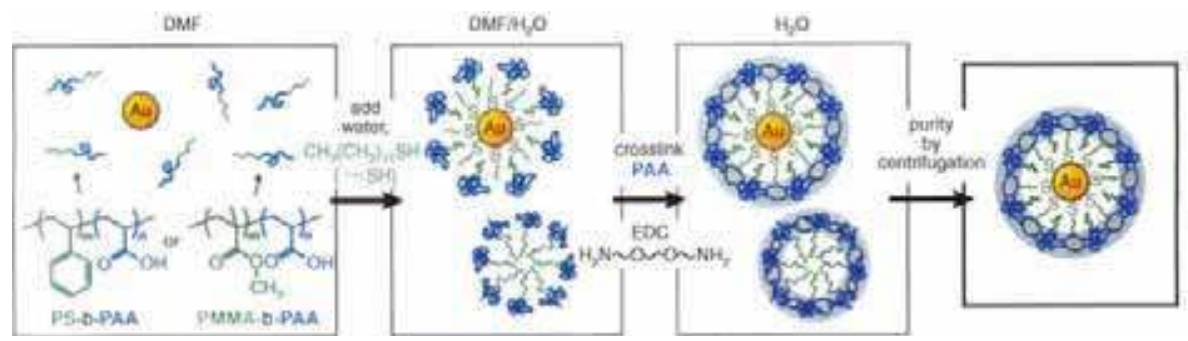

Fig. 5. Preparation of core/shell Au NPs using PS- $b$-PAA (Kang \& Taton, Angew. Chem. Int. Edit., 2005, 44, 409. Copyright Wiley-VCH Verlag GmbH \& Co. KGaA. Reproduced with permission.)

As an another example of the ligand exchange,the NPs in the original phase can be transferred to the second phase, e.g., by exchanging hydrophilicinto hydrophobic ligands. Commonly used ligand molecules include thiol groups that bind strongly to inorganic 
surfaces of NPs such asAu, Ag and CdSe, replacing the weaker bound ligands that the NPsusually have from synthesis.Underwood and Mulvaney have reported the phase transferred $\mathrm{Au}$ NPsfrom aqueous solution to organic solutionssuch as butyl acetate, carbon disulfide using a copolymer consisting of a backbone of methyl methacrylate and glycidyl methacrylate with pendant side chains of poly(12-hydroxystearic acid) (Underwood \& Mulvaney, 1994). Kumar et al. demonstrated the phase transfer of various NPs, e.g. CdS into petroleum ether using octadecanethiol (Kumar et al., 2000), Ag into hexane using octadecaneamine (Kumar et al., 2003) and Pt into hexane using octadecaneamine (Kumar et al., 2004) from aqueous solution. In some applications that require the compatibility with biological systems, it is desirable that NPs synthesized in organic solvents are transferred to aqueous solutions. Kanaras et al. have transferred theAu NPs from toluene to aqueous phase using monohydroxy (1-mercaptoundec-11-yl) tetraethylene glycol (Kanaras et al., 2002) and Algar and Krull succeed in transferring the CdSe/ZnS quantum dots from toluene to aqueous solution with mercaptoacetic acid (MAA), mercaptosuccinic acid (MSA), and dihydrolipoic acid (DHLA) (Algar \& Krull, 2006).

\subsection{Templating approach}

In "templating" method, polymers such as di- or triblock copolymer micelles, star polymers and dendrimers are used as the templates during the synthesis of Au NPs. These polymers are also referred to as "nanoreactor", since this approach uses the affinity between specific part of polymer and the gold precursor, $\mathrm{HAuCl}_{4}$ or $\mathrm{KAuCl}_{4}$, and thus reduced $\mathrm{Au}$ NPs are fixed within the nano-templates. This approach can provide controlled sizes, a narrow size distribution and long term stability of Au NPs as well as fabrication of single or multi gold core/polymer hybrid.

Poly(styrene)- $b$-poly(vinylpyridine) (PS- $b$-PVP) diblock copolymer micellesare one of the most well-known templates for NPs synthesis. Mössmer et al. fabricated the Au NPs using PS- $b$-P2VP as template (Mössmer et al., 2000). Inverse mecelles are formed from PS- $b$-P2VP diblock copolymer with a shell of PS and core of P2VP chains in toluene which is good solvent to PS and poor solvent to P2VP. By adding tetrachloroauric acid to the micelle solution, the complexation of P2VP block and $\mathrm{AuCl}_{4}$ - could be induced and reduced the Au $\mathrm{NP}$ at the core of micelle formed with subsequent addition of anhydrous hydrazine. However, without an addition of $\mathrm{HCl}$ to neutralize the excess hydrazine, $\mathrm{Au} \mathrm{NPs}$ are coagulated to groups of two to four particles which can be attributed to the coagulation of micelles from the swelling of core volume owing to the excess hydrazine. Lu and Yi also prepared the Au NPs using PS- $b$-P2VP as template (Lu \& Yi, 2006). They prepared $\mathrm{HAuCl}_{4}$ loaded PS- $b$-P2VP solution in similar way and monolayer of the micelles was produced by spin-casting onto a silicon substrate. In contrast to previous examples, the reducing step has not been used during the process to generate Au NPs in thezero-valent state. Without any post or prior reduction treatments, the $\mathrm{Au}$ NPsare formed after treatment with oxygen plasmathat alsoremove the block copolymer templates. These Au NPs have been demonstrated as catalyst system for growing small-diameter silicon nanowires. PS- $b$-P4VP micelles are also used as template to prepare Au NPs in similar approach with PS- $b$-P2VP (Hou et al., 2007). The micellization of (PS- $b$-P4VP) in chloroform can be induced by the interaction between P4VP blocks and $\mathrm{HAuCl}_{4}$, forming micelles with PS as the shell and the $\mathrm{P} 4 \mathrm{VP} / \mathrm{HAuCl}_{4}$ complex as the core. Subsequent reduction of $\mathrm{HAuCl}_{4}$ by hydrazine hydrate leads to hybrid polymeric micelles containing Au NPs in the core. The resultant hybrid polymeric micelles are quite stable in chloroform when the P4VP chains are fully protonated 


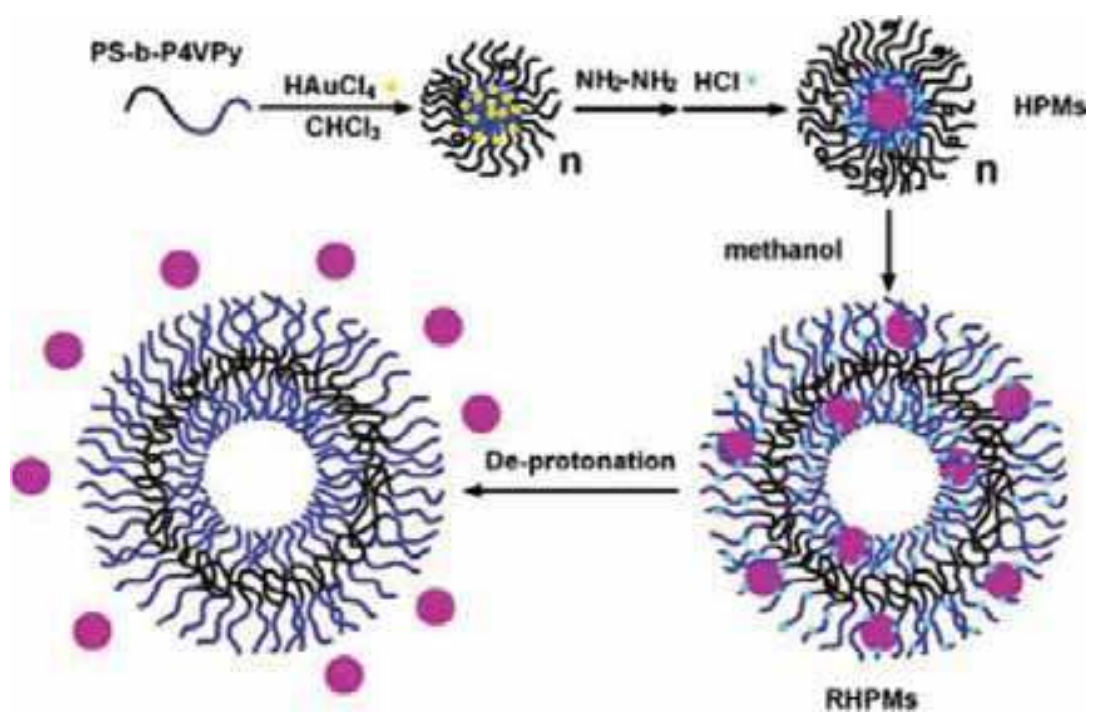

Fig. 6. Schematic description of the preparation of Au NPs in PS- $b$-P2VP micelles, vesiclelike reverse hybrid polymeric micelles, and subsequent release of Au NPs from the vesiclelike reverse hybrid polymeric micelles after deprotonation (Adapted in part with permission from Macromolecules, 2007, 40, 2134. Copyright 2007 American Chemical Society.)

by addition of hydrochloric acid. Continuous addition of methanol, where P4VP is soluble while PS is insoluble, to the solution of the hybrid micelle until the volume ratio of methanol to chloroform being 9/1 leads to a core-shell reversion of micelles, forming vesicle-like aggregates with PS as the wall and P4VP/Au NPs as the shell. Further protonation of P4VP block can induce the release of the Au NPs from the shell.

Various type of poly(ethylene oxide)- $b$-poly(propylene oxide)- $b$-poly(ethylene oxide) (PEO$b$-PPO-b-PEO) amphiphilic triblock copolymer micelles have been examined in water to prepare $\mathrm{Au}$ NPs. Sakai and Alexandridis demonstrated a sing-step synthesis of Au NPsin aqueous PEO- $b$-PPO- $b$-PEO solution (Sakai \& Alexandridis, 2004). The PEO- $b$-PPO- $b$-PEO block copolymers act as both reductants and stabilizers and they could obtain the stable $\mathrm{Au}$ NPs without any other reducing agent after 2 hours later at ambient temperature. They also investigated the effect of the overall molecular weight and the PEO and PPO block length on the reaction activity of Au NPs formation. The reaction activity increases with increasing overall molecular weight and concentration of the block copolymer, PEO block length and PPO block length. They suggested that the $\mathrm{AuCl}_{4}$-ions bound to PEO blocks are reduced via the oxidation of PEO by the metal center and PPO blocks cannot directly contribute to the reduction of metal ions but can help enhance the reactivity of the PEO blocks with metal ions, which is consistent with their observation. Regarding the effect of PEO- $b$-PPO- $b$-PEO block copolymer on the synthesis of Au NPs, they proposed that while both PEO and PPO blocks contribute to the $\mathrm{AuCl}_{4}^{-}$reduction, the PEO contribution appears to be dominant (Sakai \& Alexandridis, 2005). Chen et al. presented the effect of PEO-b-PPO-b-PEO block copolymer micelles and their hydrophobicity on the stabilization of Au NPs (Chen et al., 2006). The stabilization capacities of the micelles were modulated by tuning the block copolymer concentration and composition and an amount of salts added. As the block 


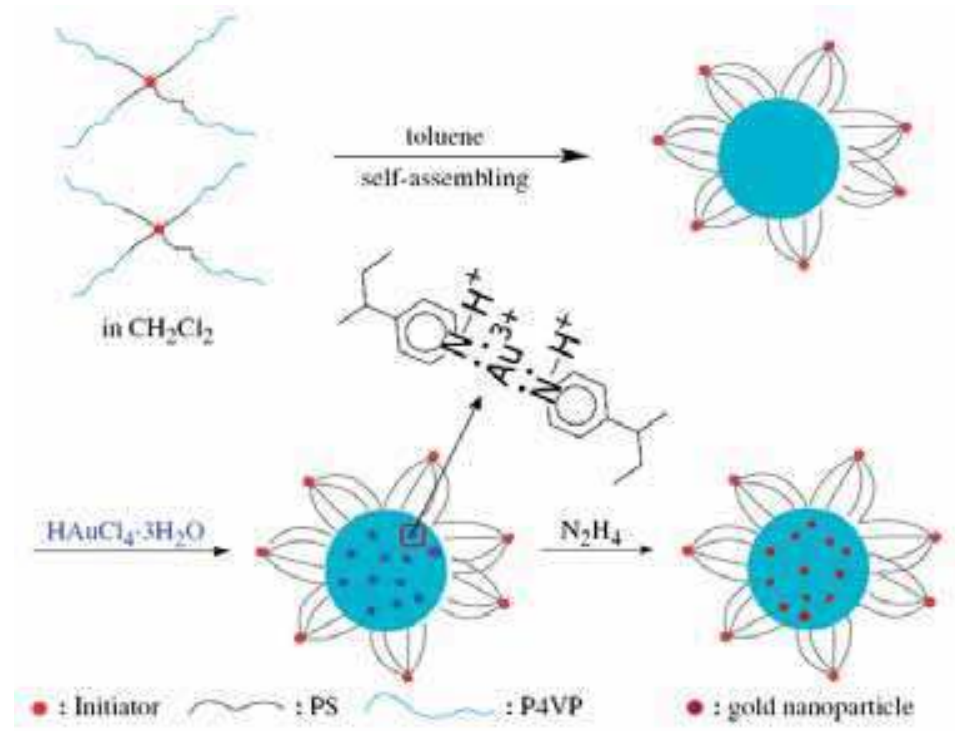

Fig. 7. Schematic representation for the preparation of reversed micelles of (PS- $b$ P4VP) ${ }_{4}$ four-arm star block copolymer and Au NPs (Reprinted from Polymer, 2006, 47, 8480 with permission from Elsevier.)

copolymer concentration and/or molecular weight increase, the micelles became more efficient in stabilizing Au NPs. When the stabilization was optimized, Au NPs were spherical and uniform in size (5-10 nm in diameter). Otherwise, Au NPs were aggregated and irregular in shape such as triangular, hexagonal, and rod-like. They also found that the presence of a small amount of NaF significantly increases the stabilization capacity of the micelles and consequently modified the quality of the Au NPs.

Star block copolymers resembled diblock copolymer micelles physically but the core segments that are covalently bound can be used in the synthesis of Au NPs to overcome the drawbacks of micelle instability which can be affected by concentration, temperature, solvent and pressure as stated above. Youk et al. synthesized the PS- $b$-P2VP star-block copolymer by living anionic polymerization and coupling with ethylene glycol dimethacrylate, forming P2VP block as core and PS block as shell (Youk et al., 2002). The $\mathrm{HAuCl}_{4}$ loaded within the P2VP core segments was reduced to single Au NPs by anhydrous hydrazine. Differing from the synthesis of Au NPs using micelles, this approach does notrequire an extra step for long-term stability such as removal of excess hydrazine and cross-linking. Fustin et al. also prepared the Au NPsin the core of poly(ethylene glycol)- $b$ poly( $\varepsilon$-caprolactone) (PEG-b-PCL) five-arm starblock copolymer in DMF (Fustin et al., 2006). The PEG core was swollen with $\mathrm{KAuCl}_{4}$ in DMF and Au NPs were subsequently obtained by reduction with $\mathrm{NaBH}_{4}$. The size distribution and long-term stability of resulting Au NPs were dependent on the PCL block length. However, these Au NPs could not be dispersed in water due to the hydrophobic PCL shell. To circumvent this problem, they grafted the hydrophilic PAA containing a trithiocarbonate moiety as another corona grafted onto the NPsand this leads to the phase transfer of the Au NPs from DMF to water.Li et al. have demonstrated the star block copolymer as nanoreactors for the preparation of Au NPs in 
different way (Li et al., 2006). They prepared the multi Au NPs in a reverse micelle of star polymers, instead of single star polymer as template for single Au NP. The (PS- $b$ P4VP) ${ }_{4}$ four-arm starblock copolymer was synthesized by ATRP ina form of four PS chain at the ends. The reverse micelles were produced by adding toluene into the dichloromethane solution of (PS- $b-\mathrm{P} 4 \mathrm{VP})_{4}$ and the structure of the micelle is kinetically frozen as dichloromethane is removed from the solution with P4VP chains (external block) as the core and PS chains (inner block) as the petal-like shell. Compared with the brush-like shell of the micelle formed by diblock copolymer, this shell has a restricted and closed structure because the chains of the same copolymer spread from the core and join at a single point. $\mathrm{HAuCl}_{4}$ was incorporated into the micelle core by forming complex with the P4VP block and reduced with anhydrous hydrazine. They observed the hybrid micelle containing dozens of small Au NPs in the core by TEM. On the contrary, Au NPs decorated in brush layer were prepared by Zhang et al. (Zhang et al., 2007). They synthesized poly(2-(dimethylamino) ethyl methacrylate) (PDMAEMA) brushes with high density on the surface of polystyrene latex by ATRP. The PDMAEMA domains were used as the nanoreactors to generate Au NPs on the surface of colloid PS particles. As indicated in aforementioned examples of "templating" method, the location and morphology of Au NPs in the templating polymer can be controlled preciously by adjusting the type, chain length, structure of polymer and the environments during the synthesis. Zheng et al. have demonstrated the template synthesis of various morphological Au NPs using a thermoresponsive and $\mathrm{pH}$ responsive coordination triblock copolymer of PEG- $b$-P4VP-b-PNIPAM (Zheng et al., 2006). They synthesized the PEG- $b$-P4VP- $b$-PNIPAM triblock copolymer which exists as three morphologies at different $\mathrm{pH}$ values and temperatures by ATRP. At $\mathrm{pH} 2.0$ and at 25 ${ }^{\circ} \mathrm{C}$,below the lower critical solution temperature (LCST) of the PNIPAM block, all three blocks are hydrophilic, and the triblock copolymer exists as unimers in aqueous solution. At $\mathrm{pH} 6.5$ and at $25^{\circ} \mathrm{C}$, the $\mathrm{pH}$-responsive P4VP block is insoluble, and the triblock copolymer self-assembles into core-shell micelles with the hydrophobic P4VP block as the core and the hydrophilic PNIPAM and PEG blocks as the shell. At pH 2.0 and at $50^{\circ} \mathrm{C}$, above the LCST of thePNIPAMblock, the triblock copolymer self-assembles into micellar clusters. The $\mathrm{HAuCl}_{4}$ made the complex with the P4VP block of the triblock copolymer, which exhibits unimer, core-shell micelles or micellar cluster at given $\mathrm{pH}$ and temperature and then reduced by $\mathrm{NaBH}_{4}$ to form discrete Au NPs, Au NPs in the core of core-shell micelle and $\mathrm{Au}$ NPs in single micellar cluster respectively.

A dendrimer was also employed to preparing the small sized Au NPs having narrow size distribution (Kim et al., 2004).They used the forth- and sixth-generation poly(aminoamine) (PAMAM) dendrimers, having about $50 \%$ of their peripheral amine groups modified with ammonium chloride, as template to prepare the Au NPs. Since they are quaternized, the dendrimers have permanent positive charges at their periphery for the extraction of aqueous $\mathrm{AuCl}_{4}$ - into the dendrimer interior. By following reduction with $\mathrm{NaBH}_{4}$, monodisperse 1-2 nm diameter Au NPs were formed.

\section{Controlling the nanoparticle location within block copolymer matrix}

\subsection{Interactions between nanoparticle and block copolymer matrix}

Block copolymer can be promising candidates for templates asthis material provides supramolecular control over the size, particle density, and spatial location of inorganic NPs, which possesses interesting photonic, magnetic, electrical, and catalytic properties. 
Therefore, hybrid materials of inorganic NPs and block copolymers have been explored as an efficient route for the fabrication of novel functional materials such as nanostructured solar cells, photonic band gap materials, highly efficient catalysts, and high density magnetic storage media. Since most applications of polymer nanocomposites described above ultimately require the integration of nanoscale components into micro- and macroscopic objects, the precise control of the spatial arrangement of inorganic NPs into two or three dimensions within polymer matrices is very crucial. The particle location within polymer matrices is determined by the interaction between the particles and the block copolymer domains, which can be divided into two different interactions of entropic and enthalpic contributions.

Balazs group is among the pioneer groups to show the importance of entropic interaction for the control of particle assembly (Thompson et al., 2001). They demonstrated thatthe control in enthalpic interaction between mesophase-forming of inorganic-organic hybrid materials can lead to well-aligned nanostructures. Thesimulation results utilizeda selfconsistent field theory (SCFT) for polymers and a density functional theory (DFT) for NPs to investigate the effect of NP size on the NP location within a block copolymer template.They claimed that conformational entropic penalty of polymer chain stretching and the translational entropy of NPs played a major role in the placementof particles within block copolymer matrix by particle size. For larger particles, they are localizedat the chain ends in the center of domain to minimize the loss of conformational entropy. In contrast, for small particles, translational entropy dominates. Therefore, they are dispersed in the preferred domain.It is shown in a 2D system representing a mixture of NPs within a lamellar block copolymer that the location of particles at the interface is expected to occur for particle size of $d / \mathrm{L}<0.2$, whereas location of the particles at the center of the domain is expected of $d / \mathrm{L}>$ 0.3 , where $d$ is the diameter of particle, and $\mathrm{L}$ is the respective domain dimension.

Bockstaller et al.demonstrated hierarchical pattern formation using block copolymers and binary mixtures of different size of hydrophobic NPs (Bockstaller et al., 2003). The system consisted of a symmetric poly(styrene- $b$-ethylene propylene) (PS-PEP) copolymer with the molecular weight of the respective blocks of $4 \times 10^{5} \mathrm{~g} / \mathrm{mol}$ as well as aliphatic coated $\mathrm{Au}$ $\left(d_{\text {core }}=3.5 \pm 1 \mathrm{~nm}\right)$ and silica $\left(d_{\text {core }}=21.5 \pm 2.5 \mathrm{~nm}\right)$ NPs. The localization of AuNPs was along the interface between the PS and PEP domains, whereas larger silica NPs are mostly located at the center of the PEP domains. Another work by Spontak group supports the entropic effect on controlling the NP location in the system of different sized polystyrene coated AuNPs within microphase-ordered PS-PEP-PS triblock copolymers (Spontak et al., 2006). Larger AuNPs (d $>5 \mathrm{~nm}$ ) are localized in the center of the PS domains, whereas smaller particles $(\mathrm{d}<3 \mathrm{~nm})$ distributed throughout the PS domains. The results are correctly predicted by the SCFT model assuming weak block selectivity of the particles. They predicted that small particles within the PS domains tend to being segregated along the interfaces, whilst larger particles are preferentially localized to the center of the PS domains. Both theory and experiment explained the control of particle location based on the competition of two different entropies, the entropy loss from the chain stretching penalty and the translational entropy of particles in polymer domains.

A much more straightforward and practical way to control the particle location is to tune the enthalpic interactions between the block copolymer and the functionalized NP surface. The most important factor lies in the compatibility of the NPs with the block copolymers, which is dominated by the enthalpic interaction between the NP surface and the block copolymer domain. 

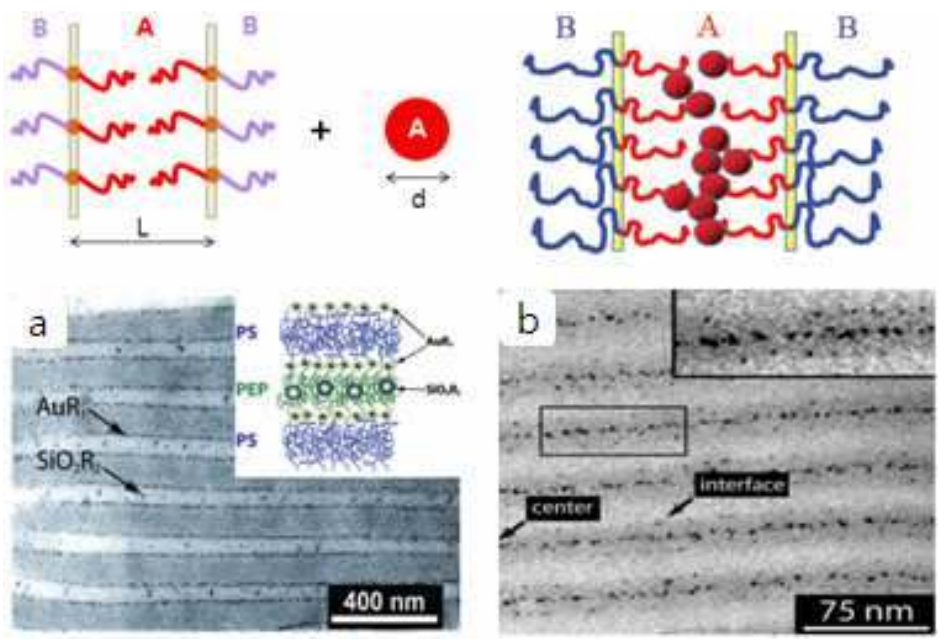

Fig. 8. Schematic representation of the entropy theory, TEM images of (a)Au and silica NPs within PS- $b$-PEP templates (Adapted in part with permission from J. Am. Chem. Soc., 2003, 125, 5276. Copyright 2003 American Chemical Society.),(b) PS coated AuNPs within PS- $b$ PEP- $b$-PS templates (Adapted in part with permission from Nano Lett., 2006, 6, 2115. Copyright 2006 American Chemical Society.).

The enthalpy interaction can be represented by Flory-Huggins interaction parameter $(\chi)$.For the system of NPs and A- $b$-B diblock copolymers, there will be two additional interaction parameters, $\chi_{\mathrm{AP}}$ and $\chi_{\mathrm{BP}}$, which represent chemical compatibility between A block and NPS and then between B block and NPs, respectively. If the NP surface is coated with A polymer and this particle is compatible with A block of the block copolymers, $X_{\mathrm{AP}}$ will be zero whereas $\chi_{\mathrm{BP}}>0$.Therefore, the NPs are segregated in A domains. On the other hand, once particles are "neutral" and the interfacial tension between two different domains of diblock copolymers is sufficiently large, particles will segregate to the interface between two phases. Since the NPs are generally coated by surfactant to shield the particles from agglomeration, the interfacial properties between the NPs and the block copolymer domains can be easily tailored by using various surfactants that provide compatibility between the NPs and polymers. As exemplified by the recent work by Kim and Kramer, a recent strategy for controlling the location of NPs in a block copolymer or polymer blend involves tuning the surface properties of NPs by end-attaching ligands such as organic small molecules, homopolymers, a mixture of homopolymers, random copolymers, and diblock copolymers to the NP surface. Kramer group showed that $100 \%$ polystyrene $\left(M_{n} \sim 1300 \mathrm{~g} / \mathrm{mol}\right)$ coated AuNPs in poly(styrene- $b-2$ vinyl pyridine) (PS- $b$-P2VP) segregated to the center of the PS domain(Chiu et al., 2005). Particles coated with a given short homopolymer lower their enthalpy by segregating into the corresponding domain of the block copolymer. Furthermore, by concentrating particles near the center of the compatible domain where the polymer ends are located, the chains can accommodate particles by moving apart rather than by stretching. Localizing particles near the center of the compatible domain thus sacrifices translational entropy of the particles but avoids an even larger chain stretching penalty incurred by distributing particles throughout the domain. In contrast, NPs that are coated with a mixture of PS and P2VP (1:1) are localized at the interfaces between the PS- $b$ - 
P2VP domains. This result can be explained by interfacial tension between PS- $b$-P2VP, AuPS and Au-P2VP (XPS-P2VP, XAu-PS, XAu-P2VP). The adsorption energy of AuNPs to the interface between PS and P2VP blocks $\left(E_{a}\right)$ can be expressed as the following equation.

$$
\mathrm{E}_{\mathrm{a}}=\Pi R^{2} \gamma_{\mathrm{PS}-\mathrm{P} 2 \mathrm{VP}}(1 \dashv \cos \phi)^{2}
$$

where $R$ is a radius of NP, and $\cos \theta$ is the ratio of the interfacial tension between NPs and polymer matrix to that between PS and P2VP. Because $|\cos \theta|<<1$ and $\mathrm{Ea} \approx \Pi R 2 \gamma \mathrm{PS}-\mathrm{P} 2 \mathrm{VP}$. The Ea of $4 \mathrm{~nm}$ radius NPs with $\gamma \mathrm{PS}-\mathrm{P} 2 \mathrm{VP}=2.8 \mathrm{mN} \mathrm{m}-1$ is $10 \mathrm{kBT}$. Therefore, PS and P2VP coated AuNPs are unlikely to be segregated along the interface.

Kim et al. also demonstrated a simple procedure to control the location of PS coated AuNPs within PS- $b$-P2VP block copolymer domains simply by changing the areal chain density (Kim et al., 2006). The areal chain density of Au particles is varied by changing the mole ratio of PS chains to $\mathrm{Au}$ atoms. The NPs completely shielded by PS chainswith high areal chain densityare segregated toward the center of the PS domain. In contrast, NPs partially shielded by PS chains withlow areal chain density are adsorbed at the interfaces between the PS and P2VP blocks. Interestingly, the particle location is sharply changed as the areal chain density is from 1.6 to 1.2 chains $/ \mathrm{nm}^{2}$.This is due to the preferential interaction between the P2VP block and the imperfectly shielded $\mathrm{Au}$ surface that is responsible for the segregation of AuNPs imperfectly shielded by PS chains to the PS and P2VP interface.
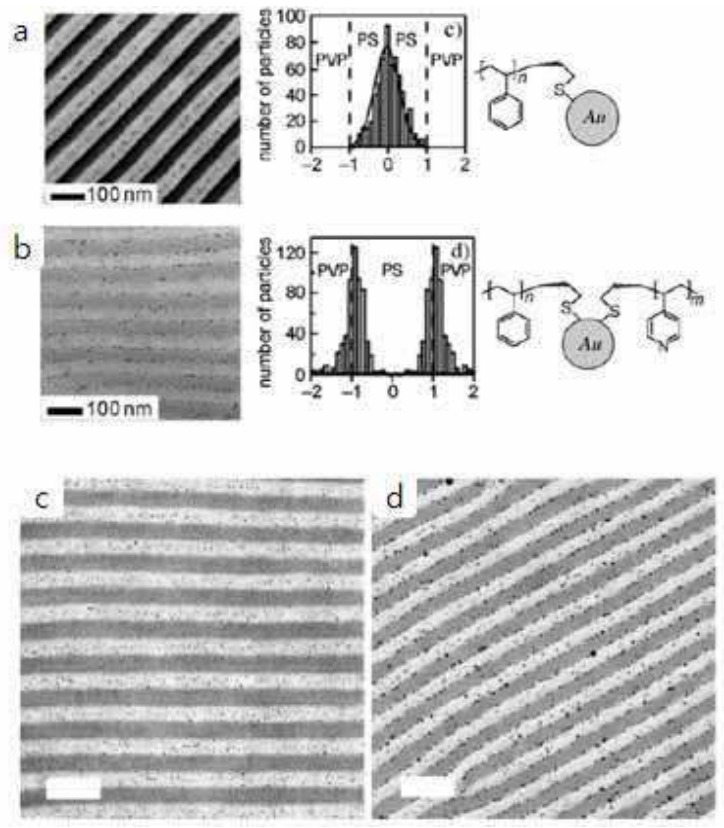

Fig. 9. (a), (b) PS or PS and P2VP mixed AuNPs within PS- $b$-P2VP (Adapted in part with permission from J. Am. Chem. Soc., 2005, 127, 5036. Copyright 2005 American Chemical Society.), Effects of areal chain densities on their position within PS-b-P2VP (c) 1.64, (d) 1.22 chains $/ \mathrm{nm}^{2}$ (Adapted in part with permission from Macromolecules, 2006, 39, 4108. Copyright 2006 American Chemical Society.). 


\subsection{Approaches for controllingthe nanoparticle distribution within block copolymer matrix}

Over the years, two approaches have been developed for incorporating inorganic NPs into polymeric nanostructures. The in-situapproach is that NPs are directly synthesized within a block copolymer domain from metal precursors. In that case, a specific and strong interaction between the precursors and the block copolymers is required to guarantee the incorporation of metal precursors into the domain. The other approach is ex-situ method where pre-synthesized and tailored NPs are incorporated into a preferred domain. In that case, tailoring materials on the surface of NPs play a critical role in particle location.

In the in-situ approach, preformed micelles of block copolymers containing metal precursors are used as nanoreactors to synthesize NPs selectively in block copolymers. Due to its chemical affinity, the salt selectively infiltrates the hydrophilic copolymer domain. The NPs then form selectively, upon reduction within the precursor-loaded domains.Schrock et al. first demonstrated the fabrication a bulk film consisting of block copolymers and inorganic NPs (Chan et al., 1992). First, the NPs are selectively incorporated in various morphologies of microdomains by ring-opening metathesis polymerization of organometallic complexes composed of norbornene and $\eta^{3}-1$-phenyallyl. Thenthe complex is annealed to form specific morphology.Finally, after reduction, NPis formed within block copolymer.They prepared $\mathrm{Pt}$ and Pd NPs in block copolymer micelles by reducing the metal salts with hydrogen while $\mathrm{Pb}$ salts incorporated in block copolymer micelles could be converted into PbS quantum dots through the reaction with $\mathrm{H}_{2} \mathrm{~S}$.Saito et al. showed the synthesis of silver NPs in the lamellar and spherical domains of PS- $b$-P2VP block copolymer using iodine as reducing agent by ion exchange in P2VP domains (Saito et al., 1992). They found that iodine ion did not exist in the PS phase but in the crosslinked P2VP phase of the crosslinked PS- $b$-P2VP film swollen in water. Then the silver NPs reduced from AgI by photo and chemical treatments arelocalized in the P2VP domains in the microphase separated PS- $b$-P2VP films. They also controlled the amount of silver NPs into the P2VP domains of PS- $b$-P2VP block copolymers by changing the amount of silver nitrate in the feed (Saito \& Ishizu, 1995).

Following this approach, Cohen et al., have developed twodimensional hexagonal patterns of metal NPs in PS- $b$-poly(acrylic acid) (PS- $b$-PAA) matrix (Boontongkong \& Cohen, 2002). The carboxyl-functionalized cores in the PAA micelle could serve as the nanoreactors for synthesis of metal NPs such as Pd, Cu, Au and Ag, and semiconductor NPs such as PbS. And Stadler et al. demonstrated the interaction between metal salts with poly(2vinylpyridine)- $b$-poly(ethylene oxide) (P2VP-b-PEO) where the size and morphology of the NPs can be controlled by $\mathrm{pH}$ change (Bronstein et al., 1997). Only a small part of the vinyl double bonds on P2VP domain has been complexed with Pd, while most of the double bonds are reacted with the Fe complex. Using same in-situ method, Sohn et al. fabricated a multilayered nanostructure of alternating pure polymeric lamellae and AuNP-containing lamellae by utilization of thin films of symmetric polystyrene- $b$-poly(4-vinyl pyridine) (PS- $b$ P4VP) (Sohn \& Seo, 2001). Strong interaction between the P4VP block and the silicon wafer substrates and lower surface energy of the PS block produced multilayers of lamellae parallel to the substrate. After annealing, AuNPs are synthesized selectively in the parallel lamellae of the P4VP block using $\mathrm{NaBH}_{4}$ as reducing agents. Recently, Fahmi et al. developed a strategy to generate AuNPs within the P4VP domains of a PS- $b$-P4VP block copolymer in solid state (Mendozaet al., 2009). The Au precursor $\left(\mathrm{HAuCl}_{4}\right)$ is coordinated in solution to the pyridine groups by hydrogen bonding, which induced its selective location within the P4VP block. Then, thermal reduction process generates metallic AuNPs, where the P4VP domain acts as a nanoreactor. 
a

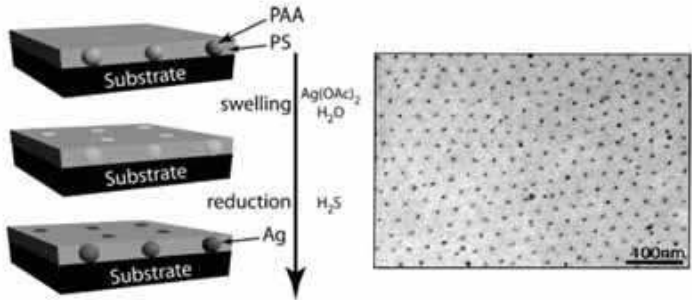

b I.

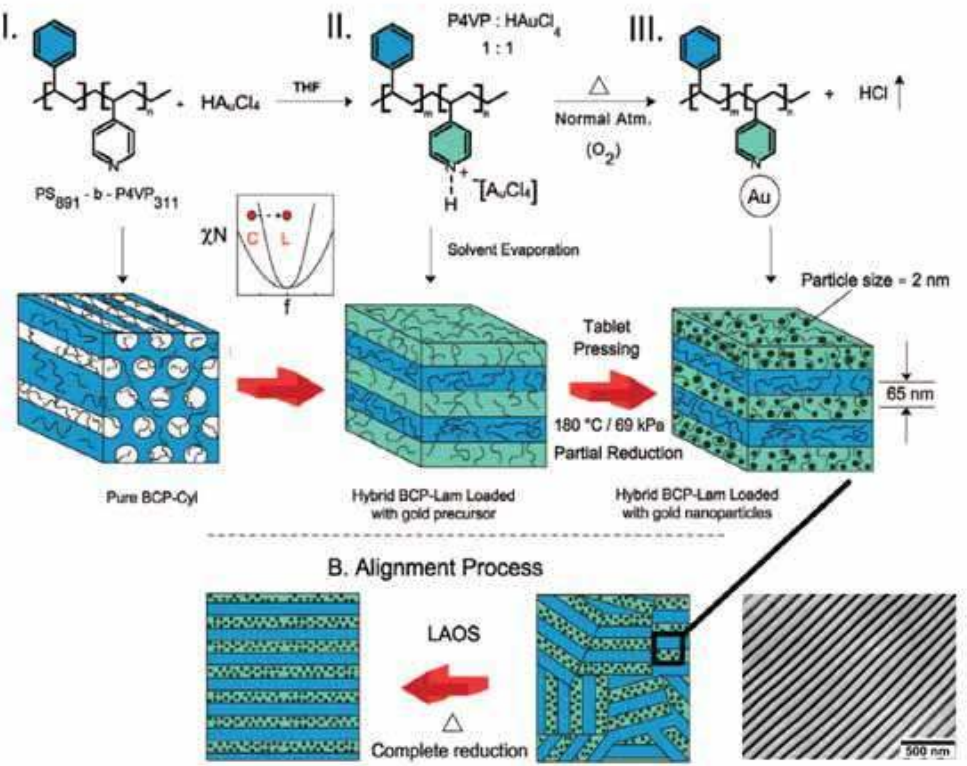

Fig. 10. (a) Synthesis of silver NPs in PS- $b$-PAA micelle (Adapted in part with permission from Macromolecules, 2002, 35, 3647. Copyright 2002 American Chemical Society.), (b)

Process of incorporating AuNPs and its subsequent macroscopic alignment (Adapted in part with permission from Macromolecules, 2009, 42, 1203. Copyright 2009 American Chemical Society.).

The in-situ approach is simple and versatile, which produces high density NP assembly within one of the block copolymer domains. However, the approach suffers from several limitations. First, controlling the arrangement of the NPs within the periodic structure of the block copolymer is difficult. Second the approach usually requiresstrong and specific interaction to bind metal precursors into one block of the block copolymer chains, which requires limited number of combinations of polymer and metal precursors or NPs. Third,the control of particle size and its uniformity could not be achieved. This aspect is critical in the sense that many applications require inorganic and/or metallic NP with well controlled size and uniformity. For example, in the case of semiconductor NPs such as quantum dot, since the photoluminescence (band gap) of a quantum dot is strongly dependent on the particles size, the particle size itself is a critical factor to determine their optical property. Therefore, it is difficult to obtain the application with desired optical propertiesby the in-situmethod. 
The $e x$-situ method of controlling the structural characteristics of the sequestered component uses cooperative self-organization of premade NPs and block copolymers. Through this method, NPs with desired size and shape coated with oligomers or polymers can be incorporated in the block copolymer matrix.Once phase separation of the copolymer has occurred, the NPs can be confined in one of the segregated domains. Clinard et al. pioneered the field of the ex-situ approach for precise placement of NPs within the block copolymer templates (Hamdoun et al., 1996). They synthesized3.5 nm diameter iron oxide NPs grafted with PS chains, which aresubsequently solubilized in the PS domain of a lamellar poly(styrene- $b$-butylmethacrylate) (PS- $b$-PBMA). However, the periodicity of the copolymer's lamellar microstructure was too small to clearly resolve the metal particles within domains. Lauter-Pasyuk introduced the small-angle neutron scattering technique to resolve the $\gamma-\mathrm{Fe}_{2} \mathrm{O}_{3} \mathrm{NP}$ location within the PS- $b$-PBMA matrix (Lauter-Pasyuk et al., 1997). They found that smaller particle sizes $(\mathrm{d}=4 \mathrm{~nm})$ tend to localize close to the interface, whereas larger particles $(\mathrm{d}=6 \mathrm{~nm})$ tend to locate at the center of the block copolymer domains.Recently, Russell groupshowed the control of block copolymer orientation in thin film by adding the surface active cadmium selenide (CdSe) NPs. Surface modified CdSe NPs with tri-n-octylphosphine oxide (TOPO) aremixed withPS- $b$-P2VP copolymer in toluene solution (Lin et al., 2005). After being casted to produce the thin films, these NPs are selectively segregated into the P2VP domain. TheCdSe NPs located at the surface of the thin films compensate the difference of surface energies between PS and P2VP domains, which resulted in the perpendicular orientation of PS- $b$-P2VP block copolymers in thin films.

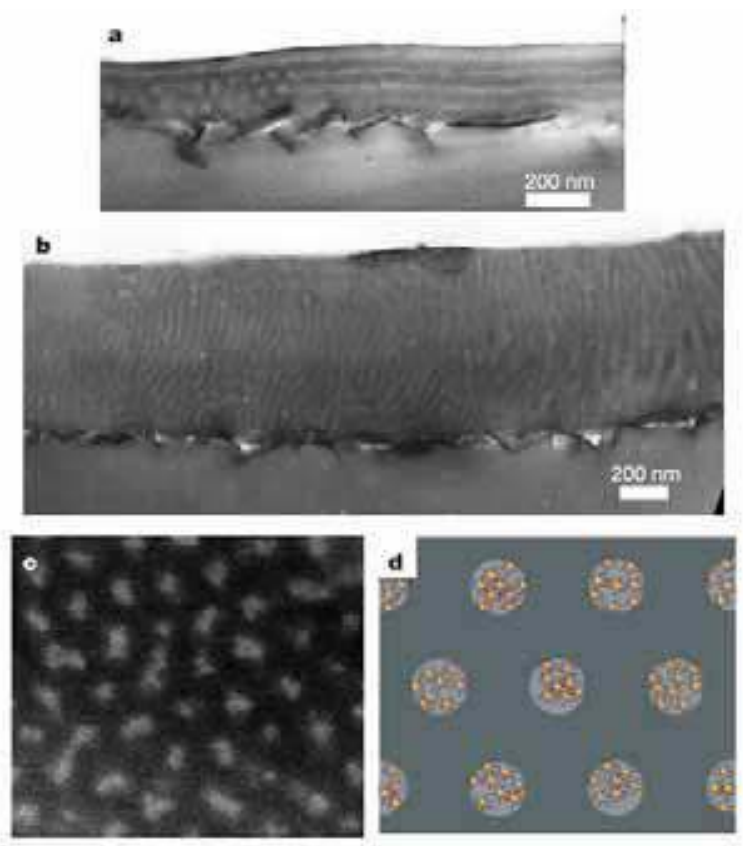

Fig. 11. PS- $b$-P2VP films with or without CdSe NP after annealing (Reprinted by permission from Macmillan Publishers Ltd: Nature, 2005, 434, 55, copyright (2005).). 
Since the ex-situ approach utilizes pre-made NPs that have desired size and shape, and uniformity, thisapproach is suitable for many applications that require inorganic and/or metallic NP with well controlled size and uniformity. Furthermore, the location of NPs within block copolymer matrix can be easily and precisely controlled by tailoring the surface properties of the NPs. However, due to the steric hindrance between the core-shell type NPs and block copolymer chains, the density of NPs within the templates is expected to be much lower compared to that by the in-situ approach.In addition, if the surface modification of NPs is necessary for such precise control, the intrinsic properties of NP can be deteriorated by increase in defect sites on the surface of NPs.
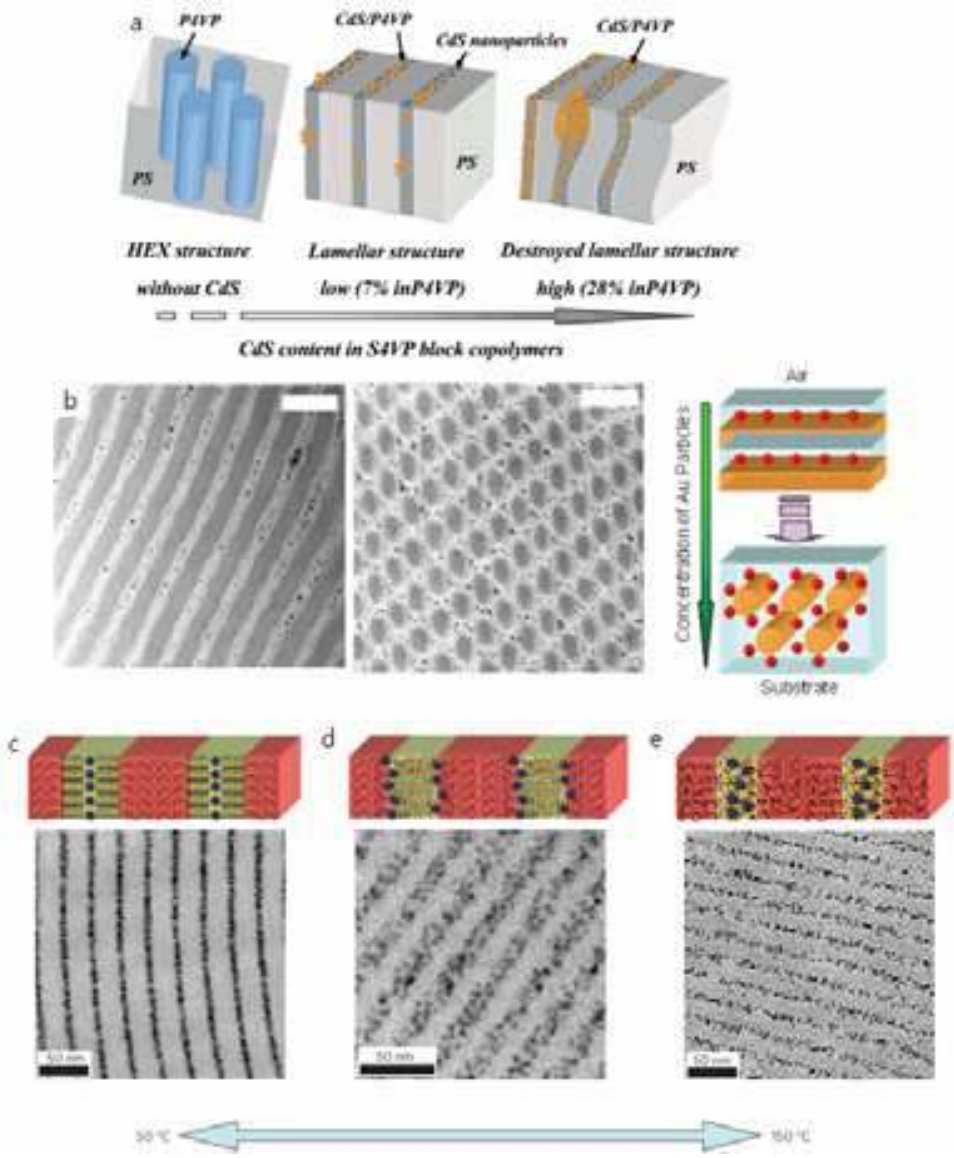

Fig. 12. (a) Schematic representation of the morphological transformation in PS- $b$-P4VP block copolymer with various ratios of CdS NPs (Adapted in part with permission from Macromolecules, 2005, 38, 6559. Copyright 2005 American Chemical Society.), (b) Phase transition in PS-b-P2VP with various concentrations of AuNPs (Kim et al., Adv. Mater., 2005, 17, 2618. Copyright Wiley-VCH Verlag GmbH \& Co. KGaA. Reproduced with permission.) TEM images and schematic representation of the PS- $b$-P4VP/CdSe NPs annealed at (c) 50 ${ }^{\circ} \mathrm{C}$, (d) $110^{\circ} \mathrm{C}$, and (e) $150^{\circ} \mathrm{C}$ (Reprinted by permission from Macmillan Publishers Ltd: Nat. Mater., 2009, 8, 979, copyright (2009).). 
The NPs with precisely controlled location can influence on the morphology of block copolymers. For example, the NPs selectively localized in one specific domain of the block copolymer templates can behave as homopolymer additives, thus causing the transition of the phase morphology of block copolymers. For example, Yeh et al. have reported morphology transformation from cylinders to spheres in the case of PS- $b$-PEO thin films by added cadmium sulfide (CdS) NPs localized in PEO domain (Yeh et al., 2004). Here, the selective placement of the CdS particles is achieved by strong interaction of thehydrogen bonding between the surface hydroxylated cadmium sulfide (CdS) NPs and the PEO phase. They also reported a morphology change from cylinder to lamellae when more CdS NPs areadded to PS- $b$-P4VP block copolymer film, in which there exists the strong hydrogen bond formation between CdS and the minor block copolymer phase (P4VP) (Yeh et al., 2005). In other work, hexagonal morphology is changed to spherical morphology by adding $\mathrm{C}_{60}$ fullerenes to PS- $b$-P4VP block copolymer system. In this case, the morphology change is attributed to $\mathrm{C}_{60}$ forming charge-transfer complexes with multiple pyridine groups from different P4VP chains (Laiho et al., 2006). Similarlythe morphology of PS- $b$-P4VP with PS coated AuNPs depends on the particle concentration and composition of block copolymers is reported by Lo et al. (Lo et al., 2007). The PS domains are filled with NPs, while at the same time,the addition of NPsexpand PS domain and change the interfacial curvature between PS and P4VP, which induced order-order transitions. However, at higher concentration, the excess particles form macrophase separation, which leads to a disordered phase.Interestingly, Kim et al. showeda phase transition of PS- $b$-P2VP block copolymers as a function offilm depthin single $100 \mu \mathrm{m}$ thick film (Kim et al., 2005). Here, the NPs are coated with PS homopolymers and therefore are selectively localized within PS domain. As the depth increases, the concentration of PS NPs within the block copolymer domains increases. Therefore, at low concentrations near the film surface, the block copolymer morphology is lamellar, just as it was in the absence of NPs. In contrast, hexagonal or spherical micellar structures with higher particle concentration are observed near the substrate layers.

In addition to the Flory-Huggins type enthalpic interaction, strong interaction such as hydrogen bonding can be applied to strengthen the interaction between NPsurface and block copolymer matrix, which resulted in better control of the NP assembly. One good example has been recently shown by Zhao et al. (Zhao et al., 2009). They utilized the strong hydrogen bonding interaction to fabricate hierarchical self-assembly of CdSe NPs within PS$b$-P4VP block copolymer. They usedtwo different molecules, 3-n-pentadecylphenol (PDP) and 4-(4'-octylphenyl)azophenol (OPAP), for coating theNP surface, wherethe NPs hydrogen bond to pyridine rings of P4VP domains. Therefore, without any further chemical modification, the CdSe NPs can be selectively sequesterated into the P4VP domain. And, interestingly, the strength of hydrogen bonding is affected by the temperature.The particle array can be tuned upon the change of the temperature, which makes the nanocomposite thermo responsive materials.

\subsection{Applications in technology}

Self-assembly of NPs into well-ordered block copolymer structures provides many interesting properties, which are different from either individual NP or polymer. Thesehybrid nanocomposites promise to be candidates for next-generation materials and provide wide applications on nanocomposite-based devices.

Since NPs such as Au, Ag have different colors with varied sizes, polymer-inorganic NPs can produce certain colors. The simulation results by Balazs group showed that the polymer- 
particle interactions affected the spatial distribution within the polyme matrix and their optical properties changed according to the particle distribution (Buxton et al., 2003). When the particles are added, band gaps are more defined with $100 \%$ reflectance with wider frequency gap. Refractive index is also crucial factor for optical application of hybrid nanocomposites. Common organic polymers have the value of 1.3 1.7, but it can be extended further if inorganic NPs are combined. For example, lead sulfide (PbS)-gelatin nanocomposites tend to increase their refractive index with increasing $\mathrm{PbS}$, and the highest values areobtained between $82-86 \%$ in $2.4-2.5$ for $\mathrm{PbS}$ fractions, whereas native gelatin has a refractive index of 1.54 (Caseri, 2000). And, Bockstaller et al. prepared metallodielectric nanocomposite materials using oligo(styrene) coated AuNP and poly(styrene- $b$ ethylene/propylene) (PS-b-PEP) (Bockstaller et al., 2003). The photonic properties of mesoscopically ordered nanocomposites are changed with various Au filling fractions. With increasing Au filling fraction, the wavelength of maximum reflectivity is red-shift. Kang et al. also showed a facile way of fabricating organic/inorganic hybrid 1D photonic crystal that utilized self-assembled PS- $b$-P2VP as photonic gels which takes advantage of a swelling and
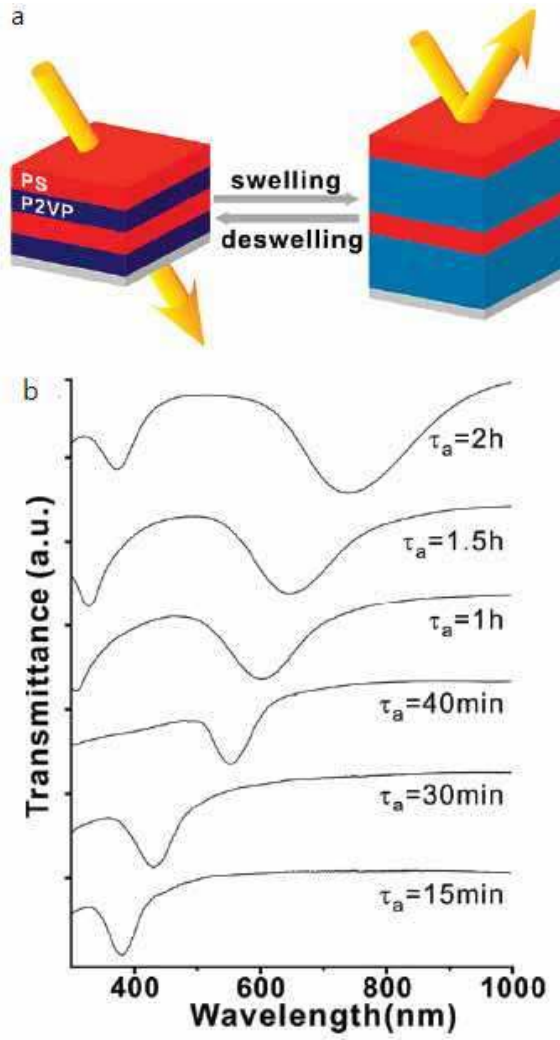
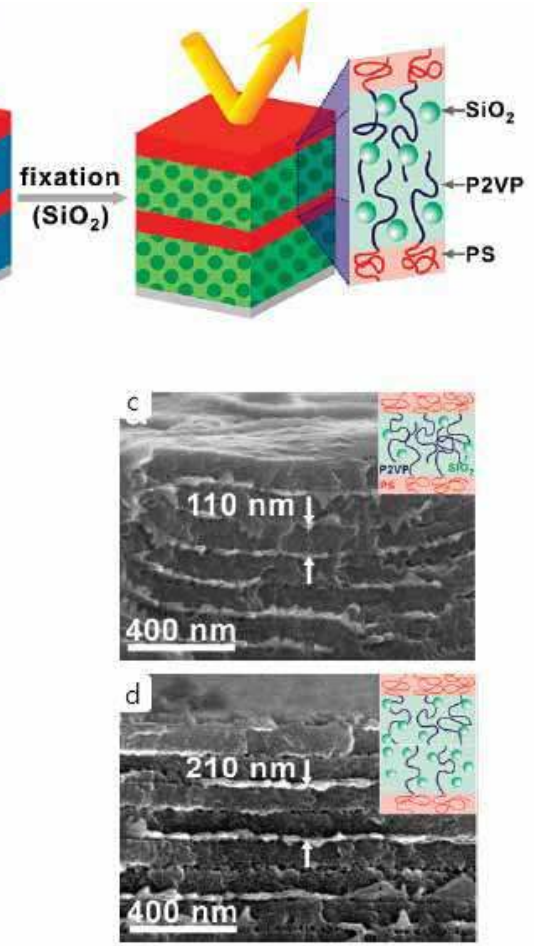

Fig. 13. (a) Schematic representation of the fabrication of photonic gels, (b) Transmittance spectra with various aging time and SEM images of photonic gels at (c) $15 \mathrm{~min}$, (d) $45 \mathrm{~min}$ (Adapted in part with permission from J. Am. Chem. Soc., 2009, 131, 7538. Copyright 2009 American Chemical Society.). 
freezing process ofsilica NPs within P2VP domains(Kang et al., 2009). These nanocomposites cancontrol the position of stop bands in transmittance spectra with increasing aging time. At longer aging time, the amount of silica NP within the P2VP domains gradually increased, and accordingly the domain size and the overall periodicity also increased.

Some polymers can change their morphology or chain length in different environment such as $\mathrm{pH}$ or temperature, which makes them suitable for bio-applications. Especially, NPs within polymeric micelles formed from amphiphilic block copolymers in water are regarded as vehicle systems for drug delivery because the micellar core segregated from the aqueous phase can serve as a reservoir of hydrophobic drugs. Kakizawa et al. showed the first example of the organic-inorganic hybrid NPs intended to be utilized as synthetic DNA carriers using calcium phosphate crystals $(\mathrm{CaP})$ and poly(ethylene glycol)- $b$-poly(aspartic acid) (PEG-b-PAA) (Kakizawa \& Kataoka, 2002). In this study, CaP surrounded by

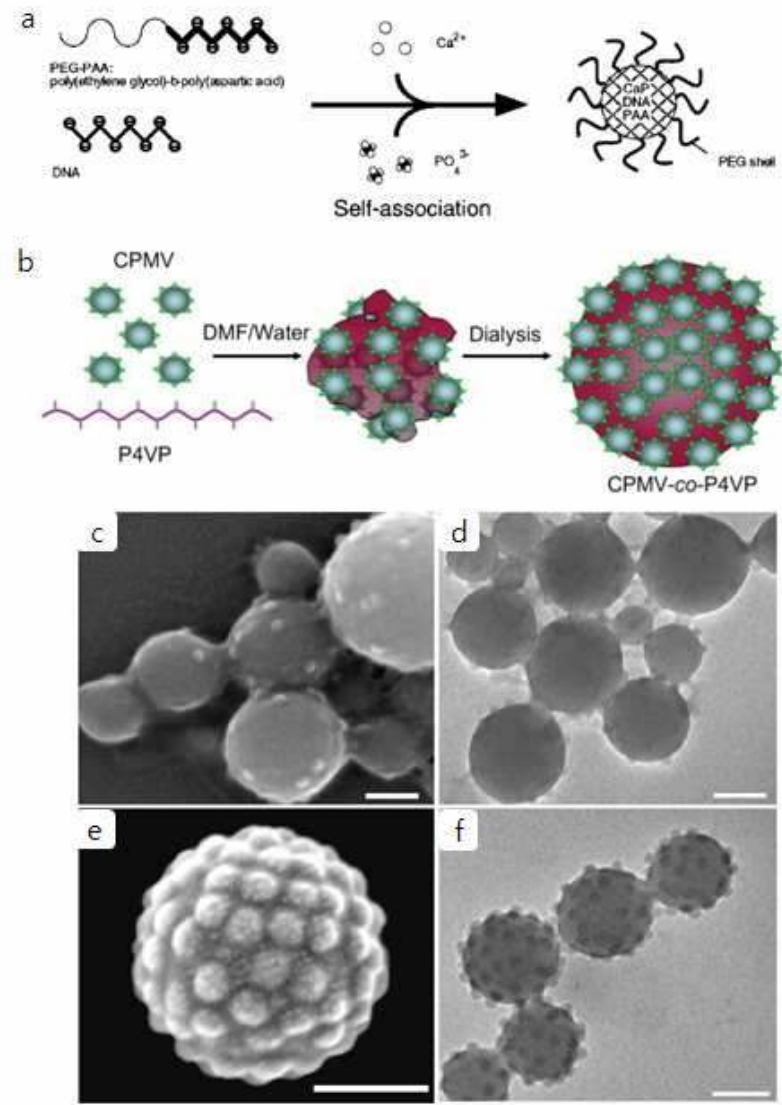

Fig. 14. (a) Schematic representation of the formation of PEG-PAA/CaP-DNA particles (Adapted in part with permission from Langmuir, 2002, 18, 4539. Copyright 2002 American Chemical Society.), (b) Schematic representation of the formation of CPMV-b-P4VP and (c)(f) their TEM images (Li et al., Small, 2008, 4, 1624. Copyright Wiley-VCH Verlag GmbH \& Co. KGaA. Reproduced with permission.). 
hydrophilic polymer palisades with block copolymers has the ability to incorporate DNA in the core. $\mathrm{Li}$ et al. demonstated the raspberry-like assemblies of virus-polymer nanocomposites based on noncovalent interactions between NPs and polymers (Li et al., 2008). They used cowpea mosaic virus (CPMC) with $29 \mathrm{~nm}$ in diameter as NP, and P4VP as polymer. This core/shell type biocomposites can be applied in drug delivery by controlling $\mathrm{pH}$-sensitive P4VP polymer resulting in release of drugs from the core.Willner et al.showed for the first time that the semiconductor NPs and enzyme complex can be applied as biosensor. (Pardo-Yissar et al., 2003). He worked on enzyme restrainer using acetylcholine esterase (AChE) / CdS complex, where the AChE/CdS complex determinedthe quantity of photocurrent according to concentration of acetylthio-choline. Since the enzyme restrainer can reduce the photocurrent, $\mathrm{AChE} / \mathrm{NP}$ is possible for biosensor application.
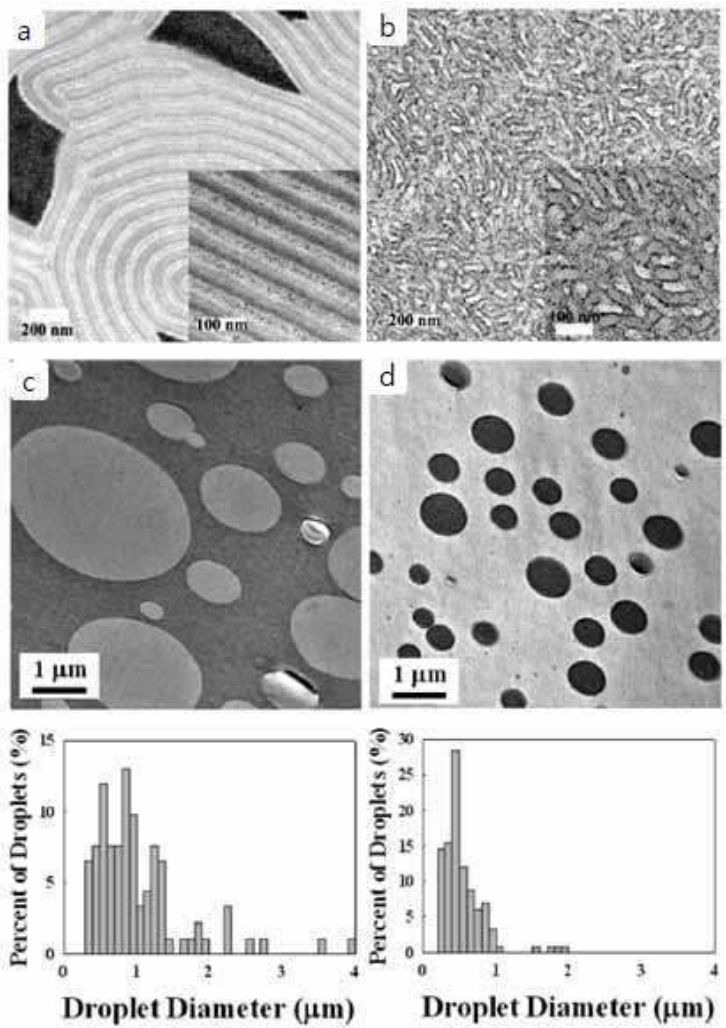

Fig. 15. PS- $b$-P2VP block copolymer with PS coated AuNPs at various volume fractions (a) 0.20, (b) 0.14 Kim (Adapted in part with permission from Langmuir, 2007, 23, 7804.

Copyright 2007 American Chemical Society.), TEM images of PS/PMMA blends (c) without or (d) with thermally stable AuNPs (Adapted in part with permission from Macromolecules, 2010, 43, 3570. Copyright 2010 American Chemical Society.)

Colloidal particles are widely used as surfactant, which blends immiscible liquids such as water and oil. Such colloidal particles are located at the interface between water and oil to lower surface energy, restrain collision between droplets composed of water or oil, and 
stabilize the system. By same principle, if NPhaving similar affinity toboth water and oil is synthesized, it can be located at the interface and used as surfactant. For example, when nanometer-scale CdSe quantum dot is added to water/toluene blend, it stabilizes the dropletsby suppressing the coalescence between the droplets and lowering the interfacial tension between the two phases (Lin et al., 2003).Park et al. showedthe controlled orientation of PS- $b$-PMMA polymers depending on the amount of PEO-coated Au NP in PS$b$-PMMA polymers (Park et al., 2007). In this case, mutual affinity between PEO-Au particle and PMMA is selective, and thus PEO-Au is located within the PMMA domain. Therefore, PS- $b$-PMMA/PEO-Au complex has a morphology of vertically well-arranged cylinder when NPs are added, just like PS- $b$-PEO in benzene/water solvent annealing. Furthermore, the
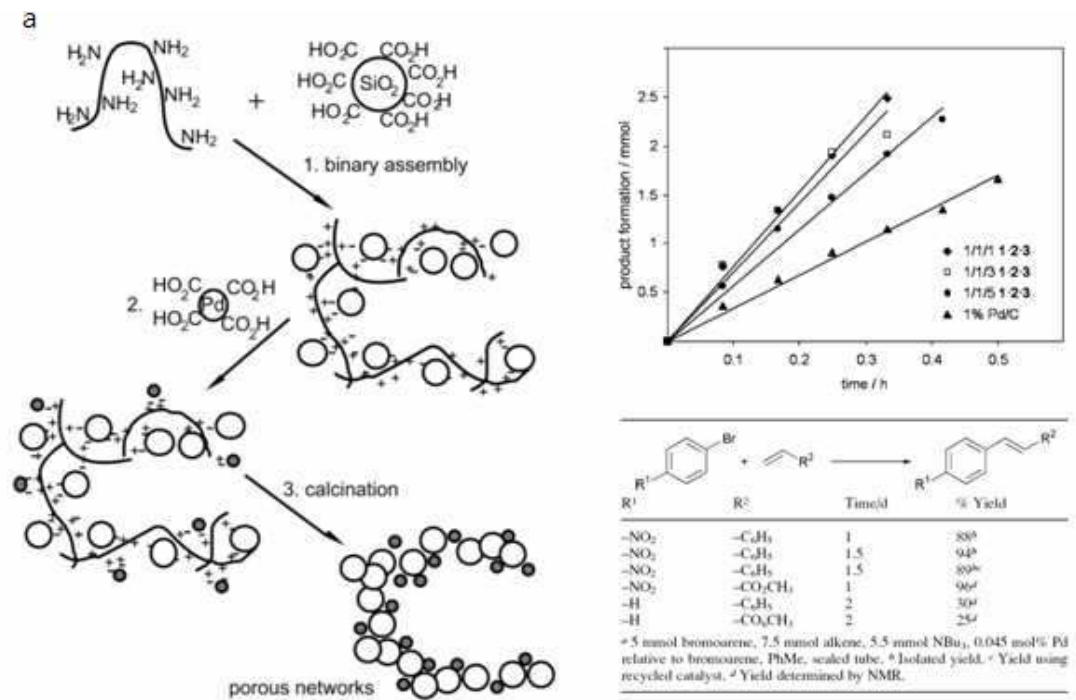

b
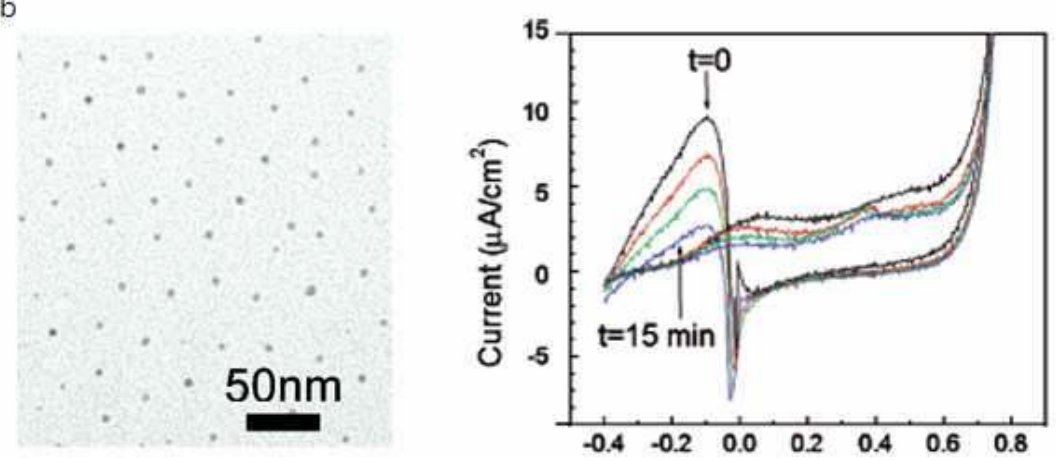

Fig. 16. (a) Schematic representation of the formation of Pd catalyst and its hydrogenation reaction for catalytic activity (Chem. Commun., 2002, 1076 - Reproduced by permission of The Royal Society of Chemistry.), (b) Electro-oxidation of carbon monoxide with AuNPs (Adapted in part with permission from J. Am. Chem. Soc., 2003, 125, 7148. Copyright 2003 American Chemical Society.) 

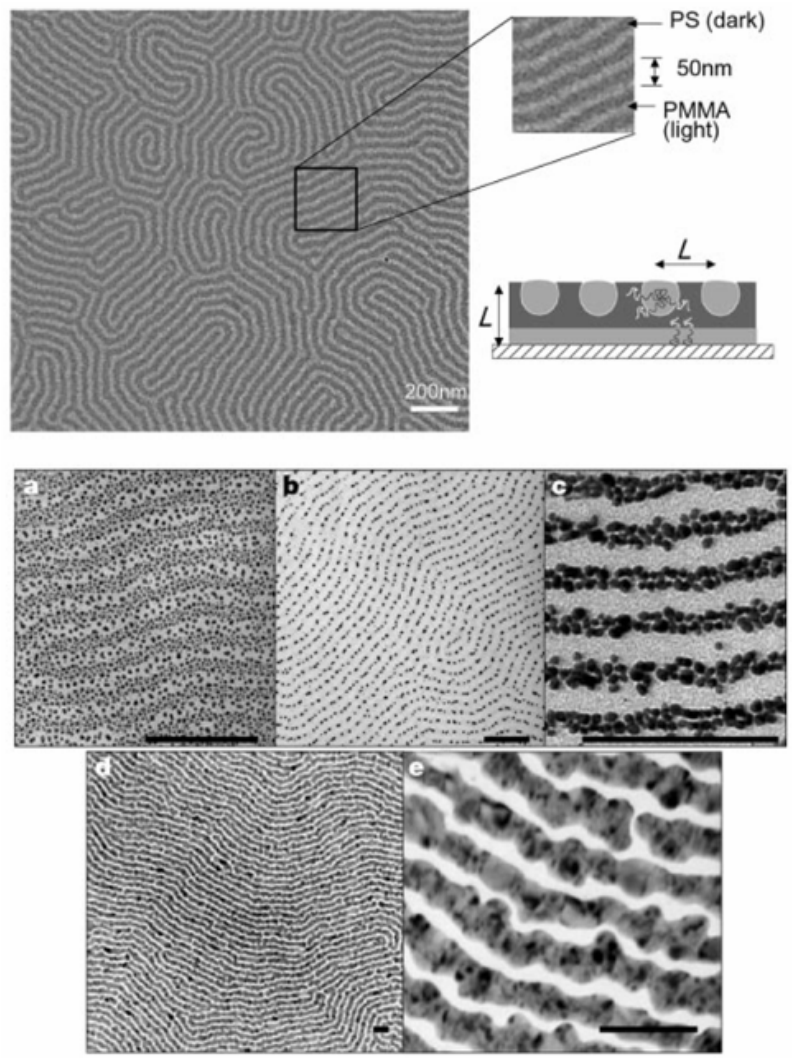

Fig. 17. Metal nanowire formation on PS- $b$-PMMAblock copolymer (Reprinted by permission from Macmillan Publishers Ltd: Nature, 2001, 414, 735, copyright (2001).)

PMMA domain of PS- $b$-PMMA/PEO-Au complex can be selectively removed to produce nanoporous template. Kim et al. showedthat the NPs at the interface of two domains of block-copolymer could be used as nanosurfactants (Kim et al., 2007). The surfactant effect is observed when AuNP is selectively introduced at the interface of lamellae-structured PS- $b$ P2VP having various molecular weights. Lamellae of block-copolymer is maintained with small quantities of NPs, but as the amount of AuNPs acting as the surfactants increases, immiscible two phases (PS and P2VP) turn into bicontinuous form. Particularly, the domain spacing of block-copolymer decreases dramatically as the amount of NP located at the interface increases, which proves that NPs act as surfactant. More recently, Yoo et al. proposed thermally stable AuNPs by introducing photo-cross-linkable azide groups as the shell on the NP surface (Yoo et al., 2010). When NPs are added into polymer blends, they are segragated at the interface between two polymers to reduce the interfacial tension between two polymer phases. As a result, the size of droplet is $0.92 \pm 0.33 \mu \mathrm{m}$ without NP, whereas $0.46 \pm 0.14 \mu \mathrm{m}$ and $0.32 \pm 0.09 \mu \mathrm{m}$ for addition of 5.0 and $10.0 \mathrm{wt} \%$ of NPs, respectively. These results suggested that thermally stable AuNPs can act as surfactants for thermally annealed PS/ PMMA blends. 
The hybrid NP/ block copolymer materials have been shown to produce the nanowire fabrication if NPs are selectively located in one domain of blockcopolymer. Particularly, if the conductive NPs are used for the fabrication of nanowire, conductivity can be improved dramatically. Jaeger et al. located Ag and Au NPs within cylindrical PS- $b$-PMMA blockcopolymer parallel to the substrate and achieved the selective arrangement (Lopes et al., 2001). First, the metal NPsare located randomly on PS-b-PMMA block copolymer and then placed selectively in PS domainparticle when heat is applied. Further annealing procedure is applied to the NP/PS- $b$-PMMA nanocomposites, where Au particles within PS domain hold together to form nanowire and consequently have high conductivity.

\section{Conclusions}

In this chapter, we described various approaches to decorate the surface of NPs, including "grafting from", "grafting to", ligand exchange, and templating approaches. Then, as an application of these NPs in nanocomposites, several efforts to control the location of NPs within block copolymer templates and their applications in various devices are reviewed. In "grafting from" approach, the desired polymers are grown from the surfaces of preformed NPs, while in "grafting from" approach,the end-functional of pre-synthesized polymers are directly used as ligands to synthesize the NPs. The other choices to modify the NPs surface can be either ligand exchange or templating methods. In ligand exchange, the requirement is that the desired ligands should have stronger interaction with NPs than the existing ligands. This method has been widely used to various NPs, such as Au, Ag, CdSe, especially when "grafting to" or "grafting from" methods are not feasible. The NPs prepared from aforementioned methods can have the desired surface properties, size, shape and uniformity, which determines the enthalpic and entropic interactionbetween the NPs and block copolymer chains and thus control their assembly within the block copolymer matrix. In this case, NPs/block copolymer hybrids are prepared via either in-situ or ex-situ methods. Interestingly, the NPs with precisely controlled location can be used as nanosurfactants between block copolymers and/or polymer blends, optical and electronic devices, and biological and catalytic applications. From these advances, it is evident thatstrategies for well-definedNPs/block copolymer hybrids promise to be candidates for next-generation materials and provide wide applications on nanocomposite-based devices.

\section{Acknowledgements}

This work was supported by the KoreaResearch Foundation Grant funded by the Korean Government (MOEHRD) (2010-0016304, 2010-0015294, 2010-0027751, 2009-0088551, 20100011033).

\section{References}

Algar, W. R. \& Krull, U. J. (2007). Luminescence and stability of aqueous thioalkyl acid capped CdSe/Zns quantum dots correlated to ligand ionization. Chem. phys. chem., Vol. 8, 561-568, 1439-4235

Aryal, S.; Bahadur, K. C. R.; Bhattarai, N.; Lee, B. M. \& Kim, H. Y. (2006). Stabilization of gold nanoparticles by thiol functionalized poly( $\varepsilon$-caprolactone) for the labeling of pcl biocarrier. Mater. Chem. Phys., Vol. 98, 463-469, 0254-0584 
Azzam, T. \& Eisenberg, A. (2007). Monolayer-protected gold nanoparticles by the selfassembly of micellar poly(ethylene oxide)- $b$-poly( $\varepsilon$-caprolactone) block copolymer. Langmuir, Vol. 23, 2126-2132, 0743-7463

Becker, C. F. W.; Marsac, Y.; Hazarika, P.; Moser, J.; Goody, R. S. \& Niemeyer, C. M. (2007). Functional immobilization of the small GTPase Rab6A on DNA-gold nanoparticles by using a site-specifically attached poly(ethylene glycol) linker and thiol placeexchange reaction. Chembiochem, Vol. 8, 32-36, 1439-4227

Bergen, J. M.; Von Recum, H. A.; Goodman, T. T.; Massey, A. P. \& Pun, S. H. (2006). Gold nanoparticles as a versatile platform for optimizing physicochemical parameters for targeted drug delivery. Macromol. Biosci., Vol. 6, 506-516, 1616-5187

Beletskaya, I. P.; Kashin, A. N.; Litvinov, A. E.; Tyurin, V. S.; Valetsky, P. M. \& Kotenll, G. (2006). Palladium colloid stabilized by block copolymer micelles as an efficient catalyst for reactions of C-C and C-heteroatom bond formation. Organometallics,Vol. 25, 154-158, 0276-7333

Bockstaller, M. R.; Lapetnikov, Y.; Margel, S. \& Thomas, E. L. (2003). Size-selective organization of enthalpic compatibilized nanocrystals in ternary block copolymer/particle mixtures. J. Am. Chem. Soc.,Vol. 125, 5276-5277, 0002-7863

Bockstaller, M. R. \& Thomas, E. L. (2003). Optical properties of polymer-based photonic nanocomposite materials. J. Phys. Chem. B,Vol. 107, 10017-10024, 1520-6106

Boontongkong, Y. \& Cohen, R. E. (2002). Cavitated block copolymer micellar thin films: lateral arrays of open nanoreactors. Macromolecules,Vol. 35, 3647-3652, 0024-9297

Bronstein, L.; Seregina, M.; Valetsky, P.; Breiner, U.; Abetz, V. \& Stadler, R. (1997). Transition metal complex induced morphology change in an ABC-triblock copolymer. Polymer Bull.,Vol. 39, 361-369, 0170-0839

Brust, M.; Fink, J.; Bethell, D.; Schiffrin, D. J.\& Kiely, C. G. (1995). Synthesis and reactions of functionalised gold nanoparticles. J. Chem. Soc., Chem. Commun., 1655-1656

Brust, M.; Walker, M.; Bethell, D.; Schiffrin, D. J. \& Whyman, R. J. (1994). Synthesis of thiolderivatized gold nanoparticles in a two phase liquid-liquid system. J. Chem. Soc., Chem. Commun., 801-802

Buxton, G. A.; Lee, J. Y.\& Balazs, A. C. (2003). Computer simulation of morphologies and optical properties of filled diblock copolymers. Macromolecules,Vol. 36, 9631-9637, 0024-9297

Caseri, W. (2000). Nanocomposites of polymers and metals or semiconductos: historical backgraound and optical properties. Macromol. Rapid Commun., Vol. 21, 705-722, 1022-1336

Chan, Y. C.; Craig, G. S. W.;Schrock, R. R. \& Cohen, R. E. (1992). Synthesis of palladium and platinum nanoclusters within microphase-separated diblock copolymers. Chem. Mater., Vol.4, 885-894, 0897-4756

Chen, S.; Guo, C.; Hu, G. H.; Wang, J.; Ma, J. H.; Liang, X. F.; Zheng, L. \& Liu, H. Z. (2006). Effect of hydrophobicity inside PEO-PPO-PEO block copolymer micelles on the stabilization of gold nanoparticles: experiments. Langmuir, Vol. 22, 9704-9711, 07437463 
Cheng, W. L.; Campolongo, M. J.; Cha, J. J.; Tan, S. J.; Umbach, C. C.; Muller, D. A. \& Luo, D. (2009). Free-standing nanoparticle superlattice sheets controlled by DNA. Nat. Mater., Vol. 8, 519-525, 1476-1122

Chiu, J. J.; Kim, B. J.;Kramer, E. J. \& Pine, D. J. (2005). Control of nanoparticle location in block copolymers. J. Am. Chem. Soc., Vol. 127, 5036-5037, 0002-7863

Corbierre, M. K.; Cameron, N. S. \& Lennox, R. B. (2004). Polymer-stabilized gold nanoparticles with high grafting densities. Langmuir, Vol. 20, 2867-2873, 0743-7463

Dong, H. C.; Zhu, M. Z.; Yoon, J. A.; Gao, H. F.; Jin, R. C. \& Matyjaszewski, K. (2008). Onepot synthesis of robust core/shell gold nanoparticles. J. Am. Chem. Soc., Vol. 130, 12852-12853, 0002-7863

Fahmi, A. W. \&Stamm, M. (2005). Spatially correlated metallic nanostructures on selfassembled diblock copolymer templates. Langmuir,Vol. 21, 1062-106, 0743-7463

Frens, G. (1973). Controlled nucleation for regulation of particle-size in monodisperse gold suspensions. Nature: Phys. Sci., Vol. 241, 20-22

Fustin, C. A.; Colard, C.; Filali, M.; Guillet, P.; Duwez, A. S.; Meier, M. A.; Schubert, U. S. \& Gohy, J. F. (2006). Tuning the hydrophilicity of gold nanoparticles templated in star block copolymers. Langmuir, Vol. 22, 6690-6695, 0743-7463

Galow, T. H.; Drechsler, U.; Hanson, J. A. \& Rotello, V. M. (2002). Highly reactive heterogeneous heck and hydrogenation catalysts constructed through 'bottom-up' nanoparticle self-assembly. Chem. Commun.,1076-1077, 1395-7345

Genson, K. L.; Holzmueller, J.; Jiang, C. Y.; Xu, J.; Gibson, J. D.; Zubarev, E. R. \& Tsukruk, V. V. (2006). Langmuir-blodgett monolayers of gold nanoparticles with amphiphilic shells from V-shaped binary polymer arms. Langmuir, Vol. 22, 7011-7015, 0743-7463

Hamdoun, B.; Ausserrè, D.; Joly, S.; Gallot, Y.; Cabuil, V. \& Clinard, C. (1996). New nanocomposite materials. J.Phys. II France, Vol. 6, 493-502, 1155-4312

Higashi, N.; Kawahara, J. \& Niwa, M. (2005). Preparation of helical peptide monolayercoated gold nanoparticles. J. Colloid Interf. Sci., Vol. 288, 83-87, 0021-9797

Higuchi, M.; Ushiba, K. \& Kawaguchi, M. (2007). Structural control of peptide-coated gold nanoparticle assemblies by the conformational transition of surface peptides. $J$. Colloid Interf. Sci., Vol. 308, 356-363, 0021-9797

Hostetler, M. J.; Templeton, A. C. \& Murray, R. W. (1999). Dynamics of place-exchange reactions on monolayer-protected gold cluster molecules. Langmuir, Vol. 15, 37823789, 0743-7463

Hou, G. L.; Zhu, L.; Chen, D. Y. \& Jiang, M. (2007). Core-shell reversion of hybrid polymeric micelles containing gold nanoparticles in the core. Macromolecules, Vol. 40, 21342140, 0024-9297

Huang, H.-M.; Chang, C.-Y.; Liu, I.-C.; Tsai, H.-C.; Lai, M.-K. \& Tsiang, R. C.-C. (2005). Synthesis of gold nanocomposite via chemisorption of gold nanoparticles with poly(p-methylstyrene) containing multiple bonding groups on the chain side. $J$. Polym. Sci.: Part A: Polym. Chem., Vol. 43, 4710-4720, 1099-0518

Hussain, I.; Graham, S.; Wang, Z.; Tan, B.; Sherrington, D. C.; Rannard, S. P.; Cooper, A. I. \& Brust, M. (2005). Size-controlled synthesis of near-monodisperse gold nanoparticles in the 1-4 nm range using polymeric stabilizers. J. Am. Chem. Soc., Vol. 127, 16398$16399,0002-7863$ 
Jaramillo, T. F.; Baeck, S.;Cuenya, B. R. \& McFarland, E. W. (2003). Catalytic activity of supported Au nanoparticles deposited from block copolymer micelles. J. Am Chem. Soc., Vol. 125, 7148-8149, 0002-7863

Kakizawa, Y.;\&Kataoka, K. (2002). Block copolymer self-assembly into monodispersive nanoparticles with hybrid core of antisense DNA and calcium phosphate. Langmuir,Vol. 18, 4539-4543, 0743-7463

Kanaras, A. G.; Kamounah, F. S.; Schaumburg, K.; Kiely, C. J. \& Brust, M. (2002). Thioalkylated tetraethylene glycol: A new ligand for water soluble monolayer protected gold clusters. Chem. Commun., 2294-2295, 1359-7345

Kang, C.; Kim, E.;Baek, H.; Hwang, K.; Kwak, D.; Kang, Y. \& Thomas, E. L. (2009). Full color stop bands in hybrid organic/inorganic block copolymer photonic gels by swellingfreezing. J. Am. Chem. Soc.,Vol. 131, 7538-7539, 0002-7863

Kang, Y. J. \& Taton, T. A. (2005). Controlling shell thickness in core-shell gold nanoparticles via surface-templated adsorption of block copolymer surfactants. Macromolecules, Vol. 38, 6115-6121, 0024-9297

Kang, Y. J. \& Taton, T. A. (2005). Core/shell gold nanoparticles by self-assembly and crosslinking of micellar, block-copolymer shells. Angew. Chem. Int. Edit., Vol. 44, 409-412, 1433-7851

Kim, B. J.; Bang, J.; Hawker, C. J. \& Kramer, E. J. (2006). Effect of areal chain density on the location of polymer-modified gold nanoparticles in a block copolymer template. Macromolecules,Vol. 39, 4108-4114, 0024-9297

Kim, B. J.; Chiu, J. J.;Yi, G. R.; Pine, D. J. \& Kramer. E. J. (2005). Nanoparticle-induced phase transitions in diblock-copolymer films. Adv. Mater.,Vol. 17, 2618-2622, 0935-9648

Kim, B. J.; Fredrickson, G. H.;Hawker, C. J. \& Kramer, E. J. (2007). Nanoparticle surfactants as a route to bicontinuous block copolymer morphologies. Langmuir,Vol. 23, 1269312703, 0743-7463

Kim, D. J.; Kang, S. M.; Kong, B.; Kim, W. J.; Paik, H. J.; Choi, H. \& Choi, I. S. (2005). Formation of thermoresponsive gold nanoparticle/pNIPAAM hybrids by surfaceinitiated, atom transfer radical polymerization in aqueous media. Macromol. Chem. Physic., Vol. 206, 1941-1946, 1022-1352

Kim, Y. G.; Oh, S. K. \& Crooks, R. M. (2004). Preparation and characterization of 1-2 nm dendrimer-encapsulated gold nanoparticles having very narrow size distributions. Chem. Mater., Vol. 16, 167-172, 0897-4756

Kotal, A.; Mandal, T. K. \& Walt, D. R. (2005). Synthesis of gold-poly(methyl methacrylate) core-shell nanoparticles by surface-confined atom transfer radical polymerization at elevated temperature. J. Polym. Sci.: Part A: Polym. Chem., Vol. 43, 3631-3642, 0887-624X

Kumar, A.; Joshi, H.; Pasricha, R.; Mandale, A. B. \& Sastry, M. (2003). Phase transfer of silver nanoparticles from aqueous to organic solutions using fatty amine molecules. J. Colloid. Interf. Sci., Vol. 264, 396-401, 0021-9797

Kumar, A.; Joshi, H. M.; Mandale, A. B.; Srivastava, R.; Adyanthaya, S. D.; Pasricha, R. \& Sastry, M. (2004). Phase transfer of platinum nanoparticles from aqueous to organic solutions using fatty amine molecules. J. Chem. Sci., Vol. 116, 293-300, 0253-4134 
Kumar, A.; Mandale, A. B. \& Sastry, M. (2000). Phase transfer of aqueous CdS nanoparticles by coordination with octadecanethiol molecules present in nonpolar organic solvents. Langmuir, Vol. 16, 9299-9302, 0743-7463

Lauter-Pasyuk, V.; Lauter, H. J.;Ausserre, D.; Gallot, Y.; Cabuil, V.; Kornilove, E. I. \& Hamdoun, B. (1997). Effects of nanoparticle size on the internal structure of copolymer-nanoparticles composite thin films studied by neutron relection. Phys. B: Condensed Matter, Vol. 241-243, 1092-1094, 0921-4526

Laiho, A.; Ras, R. H. A.;Valkama, S.; Ruokolainen, J.; Östernacka, R. \& Ikkala, O. (2006). Control of self-assembly by charge-transfer complexation between $\mathrm{C}_{60}$ fullerene and electron donating units of block copolymers. Macromolecules, Vol. 39, 7648-8653, 0024-9297

Li, D. X.; He, Q.; Cui, Y. \& Li, J. B. (2007). Fabrication of pH-responsive nanocomposites of gold nanoparticles/poly(4-vinylpyridine). Chem. Mater., Vol. 19, 412-417, 0897-4756

Li, D. X.; He, Q.; Cui, Y.; Wang, K. W.; Zhang, X. M. \& Li, J. B. (2007). Thermosensitive copolymer networks modify gold nanoparticles for nanocomposite entrapment. Chem.-Eur. J., Vol. 13, 2224-2229, 0947-6539

Li, J. B.; Shi, L. Q.; An, Y. L.; Li, Y.; Chen, X. \& Dong, H. J. (2006). Reverse micelles of starblock copolymer as nanoreactors for preparation of gold nanoparticles. Polymer, Vol. 47, 8480-8487, 0032-3861

Li, T.; Niu, Z.;Emrick, T.; Russell, T. P. \& Wang, Q. (2008). Core/shell biocomposites from the hierarchical assembly of bionanoparticles and polymer. Small,Vol. 4, 1624-1629, 0957-1329

Lin, Y.; Bőker, A.;He, J.; Sill, K.; Xiang, H.; Abetz, C.; Li, X.; Wang, J.; Emrick, T.; Long, S.; Wang, Q.; Balazs, A. \& Russell, T. P. (2005). Self-directed self-assembly of Nanoparticle/copolymer mixtures. Nature,Vol. 434, 55-59, 0028-0836

Lin, Y.; Skaff, H.;Emrick, T.; Dinsmore, A. D. \& Russell, T. P. (2003). Nanoparticle assembly and transport at liquid-liquid interfaces. Science,Vol. 229, 226-229, 0036-8075

Liu, Y. L.; Shipton, M. K.; Ryan, J.; Kaufman, E. D.; Franzen, S. \& Feldheim, D. L. (2007). Synthesis, stability, and cellular internalization of gold nanoparticles containing mixed peptide-poly(ethylene glycol) monolayers. Anal. Chem., Vol. 79, 2221-2229, 0003-2700

Lo, C.; Lee, B.;Pol, V. G.; Rago, N. L. D.; Seifert, S.; Winans, R. E. \& Thiyagarajan, P. (2007). Effect of molecular properties of block copolymers and nanoparticles on the morphology of self-assembled bulk nanocomposites. Macromolucules, Vol. 40, 83028310, 0024-9297

Lopes, W. A. \& Jaeger, H. M. (2001). Hierarchical self-assembly of metal nanostructures on diblock copolymer scaffolds. Nature, Vol 414, 735-738, 0028-0836

Lowe, A. B.; Sumerlin, B. S.; Donovan, M. S. \& McCormick, C. L. (2002). Facile preparation of transition metal nanoparticles stabilized by well-defined (co)polymers synthesized via aqueous reversible addition-fragmentation chain transfer polymerization. J. Am. Chem. Soc., Vol. 124, 11562-11563, 0002-7863

Lu, J. Q. \& Yi, S. S. (2006). Uniformly sized gold nanoparticles derived from PS- $b$-P2VP block copolymer templates for the controllable synthesis of Si nanowires. Langmuir, Vol. 22, 3951-3954, 0743-7463 
Luo, S.; Xu, J.; Zhang, Y.; Liu, S. \& Wu, C. (2005). Double hydrophilic block copolymer monolayer protected hybrid gold nanoparticles and their shell cross-linking. $J$. Phys. Chem. B, Vol. 109, 22159-22166, 1520-6106

Mednoza, C.; Pietsch, T.; Cutmann, J. S.; Jehnichen, D.; Gindy, N. \& Fahmi, A. (2009). Block copolymers with gold nanoparticles: correlation between structural characteristics and mechanical properties. Macromolecules, Vol. 42, 1203-1211, 0024-9297

Mirkin, C. A.; Letsinger, R. L.; Mucic, R. C. \& Storhoff, J. J. (1996). A DNA-based method for rationally assembling nanoparticles into macroscopic materials. Nature, Vol. 382, 607-609, 0028-0836

Mossmer, S.; Spatz, J. P.; Moller, M.; Aberle, T.; Schmidt, J. \& Burchard, W. (2000). Solution behavior of poly(styrene)-block-poly(2-vinylpyridine) micelles containing gold nanoparticles. Macromolecules, Vol. 33, 4791-4798, 0024-9297

Niidome, T.; Yamagata, M.; Okamoto, Y.; Akiyama, Y.; Takahashi, H.; Kawano, T.; Katayama, Y. \& Niidome, Y. (2006). PEG-modified gold nanorods with a stealth character for in vivo applications. J. Control. Release, Vol. 114, 343-347, 0168-3659

Park, S. C.; Kim, B. J.; Hawker, C. J.; Kramer, E. J.; Bang, J. \& Ha, J. S. (2007).Controlled ordering of block copolymer thin films by the addition of hydrophilic nanoparticles. Macromolecules, Vol. 40, 8119-8124, 0024-9297

Prasad, B. L. V.; Stoeva, S. I.; Sorensen, C. M. \& Klabunde, K. J. (2002). Digestive ripening of thiolated gold nanoparticles: The effect of alkyl chain length. Langmuir, Vol. 18, 7515-7520, 0743-7463

Raula, J.; Shan, J.; Nuopponen, M.; Niskanen, A.; Jiang, H.; Kauppinen, E. I. \& Tenhu, H. (2003). Synthesis of gold nanoparticles grafted with a thermoresponsive polymer by surface-induced reversible-addition-fragmentation chain-transfer polymerization. Langmuir, Vol. 19, 3499-3504, 0743-7463

Saito, R.; Okamura, S.\& Ishizu, K. (1992). Introduction of colloidal silver into a poly(2-vinyl pyridine) microdomain of microphase separated poly(styrene- $b$-2-vinyl pyridine) film. Polymer, Vol. 33, 1099-1101, 0032-3861

Saito, R. \& Ishizu, K. (1995). Introduction of colloidal silver into the poly(2-vinylpyridine) microdomain of microphase-separated poly(styrene- $b$-2-vinylpyridine) film: 4 . onestep method. Polymer, Vol. 36, 4119-4124, 0032-3861

Sakai, T. \& Alexandridis, P. (2004). Single-step synthesis and stabilization of metal nanoparticles in aqueous pluronic block copolymer solutions at ambient temperature. Langmuir, Vol. 20, 8426-8430, 0743-7463

Sakai, T. \& Alexandridis, P. (2005). Mechanism of gold metal ion reduction, nanoparticle growth and size control in aqueous amphiphilic block copolymer solutions at ambient conditions. J. Phys. Chem. B., Vol. 109, 7766-7777, 1520-6106

Seker, F.; Malenfant, P. R. L.; Larsen, M.; Alizadeh, A.; Conway, K.; Kulkarni, A. M.; Goddard, G. \& Garaas, R. (2005). On-demand control of optoelectronic coupling in gold nanoparticle arrays. Adv. Mater., Vol. 17, 1941-1945, 0935-9648

Shan, J.; Chen, H.; Nuopponen, M.; Viitala, T.; Jiang, H.; Peltonen, J.; Kauppinen, E. \& Tenhu, H. (2006). Optical properties of thermally responsive amphiphilic gold nanoparticles protected with polymers. Langmuir, Vol. 22, 794-801, 0743-7463 
Shan, J.; Chen, J.; Nuopponen, M. \& Tenhu, H. (2004). Two phase transitions of poly $(n-$ isopropylacrylamide) brushes bound to gold nanoparticles. Langmuir, Vol. 20, 46714676, 0743-7463

Shan, J.; Nuopponen, M.; Jiang, H.; Kauppinen, E. \& Tenhu, H. (2003). Preparation of poly(nisopropylacrylamide)-monolayer-protected gold clusters: Synthesis methods, core size, and thickness of monolayer. Macromolecules, Vol. 36, 4526-4533, 0024-9297

Shan, J.; Nuopponen, M.; Jiang, H.; Viitala, T.; Kauppinen, E.; Kontturi, K. \& Tenhu, H. (2005). Amphiphilic gold nanoparticles grafted with poly(n-isopropylacrylamide) and polystyrene. Macromolecules, Vol. 38, 2918-2926, 0024-9297

Singh, N. \& Lyon, L. A. (2007). Au nanoparticle templated synthesis of pNIPAM nanogels. Chem. Mater., Vol. 19, 719-726, 0897-4756

Sohn, B. H.\&Seo, B. H. (2001). Fabrication of the multilayered nanostructure of alternating polymers and gold nanoparticles with thin films of self-assembling diblock copolymers.Chem. Mater., Vol. 13, 1752-1757, 0897-4756

Spontak, R. J.; Shankar, R.; Bowman, M. K.;Krishnan, A. S.; Hamersky, M. W.; Samseth, J.; Bockstaller, M. R. \& Rasmussen, K. (2006). Selectivity-and size-induced segregation of molecular and nanoscale species in microphase-ordered triblock copolymers. Nano Lett.,Vol. 6, 2115-2120, 1530-6984

Thompson, R. B.; Ginzburg, V. V.;Matsen, M. W. \& Balazs, A. C. (2001). Predicting the mesophases of copolymer-nanoparticle composites. Science,Vol. 292, 2469-2472, 0036-8075

Turkevich, J.; Stevenson, P. C. \& Hillier, J. (1951). A study of the nucleation and growth processes in the synthesis of colloidal gold. Discuss. Faraday Soc., Vol. 11, 55 - 75

Underwood, S. \& Mulvaney, P. (1994). Effect of the solution refractive-index on the color of gold colloids. Langmuir, Vol. 10, 3427-3430, 0743-7463

Wan, D. C.; Fu, Q. \& Huang, J. L. (2006). Synthesis of amphiphilic hyperbranched polyglycerol polymers and their application as template for size control of gold nanoparticles. J. Appl. Polym. Sci., Vol. 101, 509-514, 0021-8995

Yee, C. K.; Jordan, R.; Ulman, A.; White, H.; King, A.; Rafailovich, M. \& Sokolov, J. (1999). Novel one-phase synthesis of thiol-functionalized gold, palladium, and iridium nanoparticles using superhydride. Langmuir, Vol. 15, 3486-3491, 0743-7463

Yeh, S.; Chang, Y.;Chou, C. \& Wei, K. (2004). Effect of surface-hydroxylated CdS nanoparticles on the morphological transformation of polystyrene-blockpoly(ethylene oxide) thin films. Macromol. Rapid Commun.,Vol. 25, 1679-1686, 10221336

Yeh, S.; Wei, K.; Sun, Y.; Jeng, U. \& Liang, K. S. (2005). CdS nanoparticles induce a morphological transformation of poly(styrene- $b$-4-vinylpyridine) from hexagonally packed cylinders to a lamellar structure. Macromolecules,Vol. 38, 6559-6565, 00249297

Yoo, M.; Kim, S.; Lim, J.; Kramer, E. J.; Hawker, C. J.; Kim, B. J. \& Bang, J. (2010). Facile synthesis of thermally stable core-shell gold nanoparticles via photo-cross-linkable polymeric ligands. Macromolecules, Vol. 43, 3570-3575, 0024-9297 
Youk, J. H.; Park, M. K.; Locklin, J.; Advincula, R.; Yang, J. \& Mays, J. (2002). Preparation of aggregation stable gold nanoparticles using star-block copolymers. Langmuir, Vol. $18,2455-2458,0743-7463$

Zhang, L. \& Lin, J. (2009). Hierachically ordered nanocomposites self-assembled from linearalternating block copolymer/nanoparticle mixture.Macromolecules,Vol. 42, 14101414, 0024-9297

Zhang, M. M.; Liu, L.; Wu, C. L.; Fu, G. Q.; Zhao, H. Y. \& He, B. L. (2007). Synthesis, characterization and application of well-defined environmentally responsive polymer brushes on the surface of colloid particles. Polymer, Vol. 48, 1989-1997, 0032-3861

Zhao, W. A.; Gao, Y.; Kandadai, S. A.; Brook, M. A. \& Li, Y. F. (2006). DNA polymerization on gold nanoparticles through rolling circle amplification: Towards novel scaffolds for three-dimensional periodic nanoassemblies. Angew. Chem. Int. Edit., Vol. 45, 2409-2413, 1433-7851

Zhao, Y.; Thorkelsson, K.;Mastroianni, A. J.; Schilling, T.; Luther, J. M.; Rancatore, B. J.; Matsunaga, K.; Jinnai, H.; Wu, Y.; Poulsen, D.; Fréchet, J. M. J., Alivisatos, A. P. \& $\mathrm{Xu}, \mathrm{T}$. (2009). Small-molecule-directed nanoparticle assembly towards stimuliresponsive nanocomposites. Nat. Mater.,Vol. 8, 979-985, 1476-1122

Zheng, P. W.; Jiang, X. W.; Zhang, X.; Zhang, W. Q. \& Shi, L. Q. (2006). Formation of gold@polymer core-shell particles and gold particle clusters on a template of thermoresponsive and $\mathrm{pH}$-responsive coordination triblock copolymer. Langmuir, Vol. 22, 9393-9396, 0743-7463

Zubarev, E. R.; Xu, J.; Sayyad, A. \& Gibson, J. D. (2006). Amphiphilic gold nanoparticles with V-shaped arms. J. Am. Chem. Soc., Vol. 128, 4958-4959, 0002-7863 


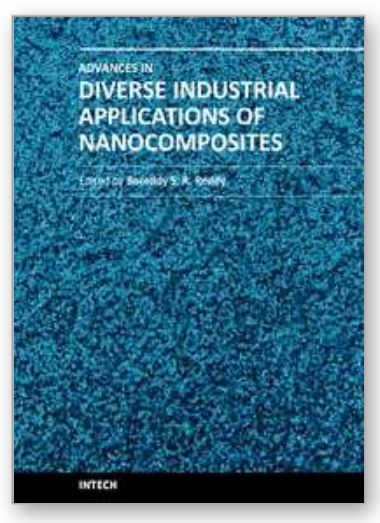

\author{
Advances in Diverse Industrial Applications of Nanocomposites \\ Edited by Dr. Boreddy Reddy
}

ISBN 978-953-307-202-9

Hard cover, 550 pages

Publisher InTech

Published online 22, March, 2011

Published in print edition March, 2011

Nanocomposites are attractive to researchers both from practical and theoretical point of view because of combination of special properties. Many efforts have been made in the last two decades using novel nanotechnology and nanoscience knowledge in order to get nanomaterials with determined functionality. This book focuses on polymer nanocomposites and their possible divergent applications. There has been enormous interest in the commercialization of nanocomposites for a variety of applications, and a number of these applications can already be found in industry. This book comprehensively deals with the divergent applications of nanocomposites comprising of 22 chapters.

\title{
How to reference
}

In order to correctly reference this scholarly work, feel free to copy and paste the following:

Misang Yoo, Joona Bang, Kwanyeul Paek and Bumjoon J. Kim (2011). A Strategy to Decorate the Surface of NPs and Control their Locations within Block Copolymer Templates, Advances in Diverse Industrial

Applications of Nanocomposites, Dr. Boreddy Reddy (Ed.), ISBN: 978-953-307-202-9, InTech, Available from: http://www.intechopen.com/books/advances-in-diverse-industrial-applications-of-nanocomposites/a-strategyto-decorate-the-surface-of-nps-and-control-their-locations-within-block-copolymer-templat

\section{INTECH}

open science | open minds

\section{InTech Europe}

University Campus STeP Ri

Slavka Krautzeka 83/A

51000 Rijeka, Croatia

Phone: +385 (51) 770447

Fax: +385 (51) 686166

www.intechopen.com

\section{InTech China}

Unit 405, Office Block, Hotel Equatorial Shanghai

No.65, Yan An Road (West), Shanghai, 200040, China 中国上海市延安西路65号上海国际贵都大饭店办公楼405单元

Phone: +86-21-62489820

Fax: $+86-21-62489821$ 
(C) 2011 The Author(s). Licensee IntechOpen. This chapter is distributed under the terms of the Creative Commons Attribution-NonCommercialShareAlike-3.0 License, which permits use, distribution and reproduction for non-commercial purposes, provided the original is properly cited and derivative works building on this content are distributed under the same license. 